ARTICLE

Received 29 May 2014 | Accepted 13 Feb 2015 | Published 8 Apr 2015 DOl: 10.1038/ncomms7643

\title{
Rio1 promotes rDNA stability and downregulates RNA polymerase I to ensure rDNA segregation
}

\author{
Maria G. lacovella ${ }^{1, \star}$, Cristina Golfieri ${ }^{1, \star, \dagger}$, Lucia F. Massari ${ }^{1}$, Sara Busnelli ${ }^{1}$, Cinzia Pagliuca ${ }^{1}$, \\ Marianna Dal Maschio ${ }^{1, \dagger}$, Valentina Infantino ${ }^{1, \dagger}$, Rosella Visintin ${ }^{1}$, Karl Mechtler ${ }^{2,3}$, Sébastien Ferreira-Cerca ${ }^{4}$ \\ $\&$ Peter De Wulf ${ }^{1}$
}

The conserved protein kinase Rio1 localizes to the cytoplasm and nucleus of eukaryotic cells. While the roles of Rio1 in the cytoplasm are well characterized, its nuclear function remains unknown. Here we show that nuclear Rio1 promotes rDNA array stability and segregation in Saccharomyces cerevisiae. During rDNA replication in S phase, Rio1 downregulates RNA polymerase I (Poll) and recruits the histone deacetylase Sir2. Both interventions ensure rDNA copy-number homeostasis and prevent the formation of extrachromosomal rDNA circles, which are linked to accelerated ageing in yeast. During anaphase, Rio1 downregulates Poll by targeting its subunit Rpa43, causing Poll to dissociate from the rDNA. By stimulating the processing of Poll-generated transcripts at the rDNA, Rio1 allows for rDNA condensation and segregation in late anaphase. These events finalize the genome transmission process. We identify Rio1 as an essential nucleolar housekeeper that integrates rDNA replication and segregation with ribosome biogenesis.

\footnotetext{
${ }^{1}$ Department of Experimental Oncology, European Institute of Oncology, via Adamello 16, Milan 20139, Italy. ${ }^{2}$ The Research Institute of Molecular Pathology, Dr Bohr-Gasse 7, Vienna 1030, Austria. ${ }^{3}$ The IMBA Institute of Molecular Biotechnology of the Austrian Academy of Sciences, Dr Bohr-Gasse 3, Vienna 1030, Austria. ${ }^{4}$ Lehrstuhl für Biochemie III, Universität Regensburg, Universitätsstraße 31, 93053 Regensburg, Germany. ${ }^{*}$ These authors contributed equally to this work. †Present addresses: German Center for Neurodegenerative Diseases (DZNE), Arnoldstraße 18/18b, 01307 Dresden, Germany (C.G.); Università degli Studi di Brescia, Sede di Medicina e Chirugia, Viale Europa 11, 25123 Brescia, Italy (M.D.M.); Department of Cell Biology, University of Geneva, 30 Quai ErnestAnsermet CH-1211, Geneva 4, Switzerland (V.I.). Correspondence and requests for materials should be addressed to P.D.W. (email: peter.dewulf@ieo.eu)
} 
$\mathrm{t}$ anaphase onset, the replicated chromosomes separate and then segregate along the mitotic spindle into the daughter cells. In the budding yeast Saccharomyces cerevisiae, the locus containing the genes that encode the ribosomal RNAs (rDNA) segregates after the rest of the genome, in late anaphase $\mathrm{e}^{1-4}$. The rDNA locus exists as a tandem-repeat array comprising $\sim 150$ rDNA units containing the $35 \mathrm{~S}$ and $5 \mathrm{~S}$ genes, which are transcribed by RNA polymerase I (PolI) and PolIII, respectively. Processing of the $35 \mathrm{~S}$ pre-rRNA generates $5.8 \mathrm{~S}, 18 \mathrm{~S}$ and $25 \mathrm{~S}$ rRNA that, together with the $5 \mathrm{~S}$ rRNA, become the catalytic backbones of each ribosome $e^{5,6}$. Only in anaphase does yeast repress rDNA transcription ${ }^{4}$, which allows the sister rDNA loci to condensate and segregate. PolI downregulation in anaphase is mediated by the Cdc14 phosphatase acting on PolI subunit Rpa43 (ref. 4), resulting in PolI dissociating from the $35 \mathrm{~S}$ rDNA. The removal of PolI and the local resolution of its transcripts allow the condensin complex to bind. The latter compacts the rDNA array and recruits the DNA decatenating enzyme topoisomerase II (refs $1,3,4,7$ ) resulting in the physical separation and subsequent segregation of the sister rDNA loci.

S. cerevisiae Riol belongs to the atypical RIO protein kinase family whose members lack the activation loop and substrate recognition domain present in canonical eukaryotic protein kinases $^{8-11}$. Noteworthy, the RIO kinases may act especially as ATPases as they exhibit $<0.1 \%$ kinase activity in vitro ${ }^{12-14}$. Cytoplasmic Rio1 contributes to pre-40S ribosome biogenesis by promoting $20 \mathrm{~S}$ pre-rRNA maturation and by stimulating the recycling of trans-acting factors at the pre-40S subunit, both in yeast ${ }^{12,15-18}$ and human cells ${ }^{19,20}$. Roles in the nucleus are unknown for any RIO member, either in yeast or eukaryotes beyond. Using S. cerevisiae, we now describe the first activities of Rio1 in the nucleus. Foremost, Rio1 downregulates PolI transcription through the cell cycle. In G1, Rio1 additionally promotes pre-rRNA processing to ensure a timely commencement of the cell cycle. In S phase, besides downregulating PolI, Riol also recruits the histone deacetylase Sir2 to ensure rDNA repeatnumber stability. In anaphase, the downregulation of PolI by Rio1 and its activation of pre-rRNA processing drive rDNA condensation and segregation. Cells lacking nuclear Riol activity suffer from a delayed cell cycle entry, fragmented nucleolus, an expanded rDNA array, extrachromosomal rDNA circles (ERCs) and an inability to segregate rDNA. We identify Riol as an essential nucleolar housekeeper of rDNA integrity and transmission, and as an upstream regulator of ribosome biogenesis.

\section{Results}

Rio1 localizes dynamically to rDNA during the cell cycle. Previous work showed that substituting conserved catalytic residue D244E in the Riol kinase domain provoked plasmid loss in $S$. cerevisiae $^{21}$, suggesting an involvement of Riol in DNA replication and/or segregation. To examine this possibility, we imaged Rio1, labeled with green fluorescent protein (Rio1-GFP), in exponentially growing $S$. cerevisiae cells. We identified the protein both in the cytoplasm (consistent with its documented involvement in $20 \mathrm{~S}$ pre-rRNA maturation ${ }^{15}$ and pre-40S ribosome trans-factor recycling ${ }^{12,17,18}$ ), and in the nucleus (Fig. 1a). As the intranuclear localization of Riol could not be easily determined, we isolated the nuclei from exponentially grown yeast, crosslinked and then spread them on glass slides. Immunofluorescence (IF) microscopy with an anti-Riol antibody revealed that Riol was highly enriched at the nucleolus (colocalized with nucleolar marker Nop1; Fig. 1b), the subnuclear compartment that is organized around the rDNA array (Supplementary Fig. 1). However, Riol signal intensities were heterogeneous across the nuclei suggesting a cell cycle-dependent localization. To probe this observation further, 6myc-Riol cells were arrested in G1 with $\alpha$-factor and then synchronously released into the cell cycle. Samples were taken during cell cycle progression, the nuclei were isolated, spread and analysed by antimyc IF imaging (Fig. 1c,d). We observed that Riol was highly enriched at the nucleolus in G1. Riol signals then decreased by half through $\mathrm{S}$ phase. In metaphase, the nucleoli contained very low amounts of Rio1, whereas at anaphase onset Riol became actively re-recruited to the nucleolus, reaching levels similar to those measured in G1 (Fig. 1c,d and Supplementary Fig. 2a). Low amounts of Riol were detectable in the nucleus (beyond the nucleolus), especially in S phase (Fig. 1d). Using chromatin immunoprecipitation (ChIP) analysis, we next probed to which sites Rio1 localized at the rDNA. 6myc-Riol cells were arrested in G1, S phase, metaphase and anaphase (via use of $\alpha$-factor, hydroxyurea, nocodazole and the $c d c 15-2$ allele, respectively). The rDNA sequences that were enriched with immunoprecipitated Riol were identified by real-time quantitative PCR (RT-qPCR) analysis using probes covering the rDNA unit. While the 6mycRiol signals were distributed homogeneously across the rDNA in G1 and metaphase cells, we found the kinase to be enriched at the $35 \mathrm{~S}$ rDNA promoter and gene sequence (probes 4 and 5) in S phase and anaphase (coloured lines in Fig. 1e). However, the averaged values obtained with the five probes (black bars in Fig. 1e) confirmed the Riol localization dynamics observed by imaging of the spread nuclei.

A previous report indicated that Rio1, overexpressed from the $P_{\text {GAL10 }}$ promoter, becomes degraded in S phase, suggesting Riol stability is cell cycle regulated $^{22}$. However, our western blot analyses of yeast endogenously expressing Riol showed that its protein levels do not change through the cell cycle (Fig. 1f). Hence, the observed dynamic localization of Riol may reflect changes in its affinity for nucleolar factors and/or its active import-export from the nucleus. Riol shuttling between the nucleus and cytoplasm was evidenced previously by its intranuclear accumulation in an exportin mutant ${ }^{16}$.

Besides its localization, a role for Riol at the rDNA was indicated by its recent co-purification with the phosphatase Cdc14 and its inhibitor Cfil (ref. 23), which together with the histone deacetylase Sir2 form the rDNA-silencing complex RENT $^{24}$ (Fig. 1g). Our own yeast two-hybrid screens that used Riol as the bait (Supplementary Fig. 2b) identified as interactors the rDNA helicase Sgs1 (confirmed by co-immunoprecipitation from yeast whole-cell extract; Supplementary Fig. 2c), the rDNAsilencing protein Tof2 and Rio1 itself (Supplementary Fig. 2b). These findings extend the current Riol protein-interaction map that mostly comprises ribosome biogenesis factors ${ }^{25}$ (Fig. 1g).

Distinct sets of nucleolar proteins recruit Rio1. While the 150unit repeat nature of the rDNA array satisfies yeast's huge demand for ribosomes ${ }^{26}$, its configuration makes rDNA highly vulnerable to genetic instability during rDNA replication ${ }^{27,28}$. Although the replication fork moves bi-directionally from the rARS, the leftward-moving replisome is halted at the replication fork barrier site (RFB) to prevent it from colliding with PolI, transcribing the $35 \mathrm{~S}$ rDNA sequence in rightward direction. Such a collision would generate incomplete $35 \mathrm{~S}$ rRNA transcripts and produce double-strand breaks in the $35 \mathrm{~S}$ unit. However, the replisome held at the RFB may collapse, resulting in the exposure of single-strand rDNA, progressing into a double-strand break. Double-strand DNA breaks are repaired by homologous recombination. For a correct repair to occur, the sister rDNA loci must be aligned. If not, homologous recombination will result in an expansion or contraction of the rDNA array and in the formation of $\mathrm{ERCs}^{27,28}$, anomalies that have been linked to a 
a

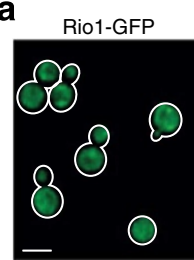

b

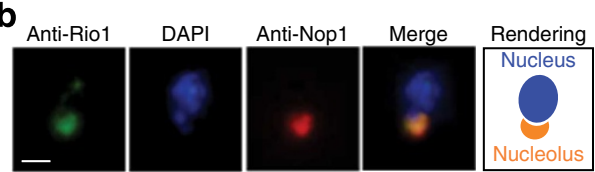

C

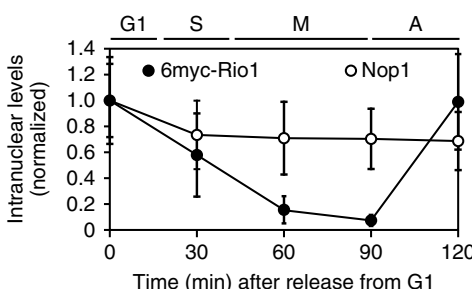

d

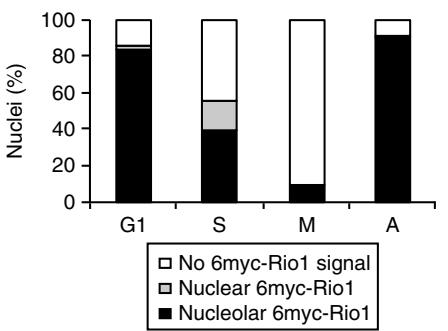

e
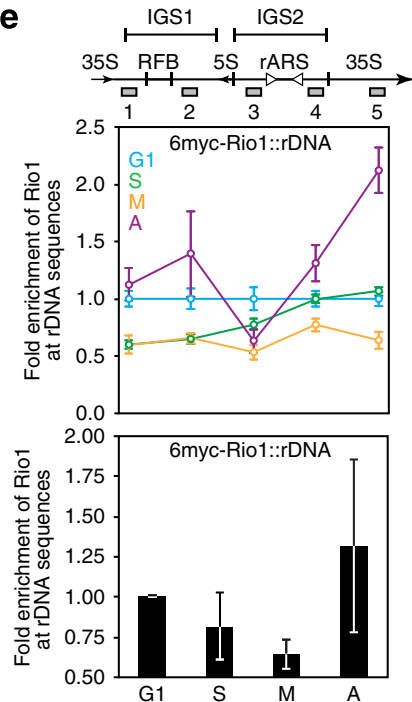

f

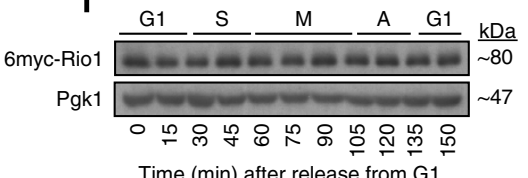

Time ( $\mathrm{min}$ ) after release from $\mathrm{G} 1$

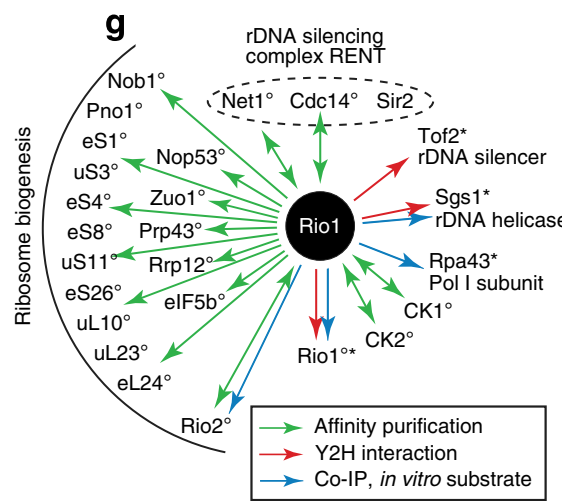

Figure 1 | Rio1 localizes to the rDNA in a dynamic, cell cycle stage-dependent manner. (a) Fluorescence microscopy image of DAPI-stained exponentially growing yeast cells endogenously expressing Rio1-GFP. Scale bar, $5 \mu \mathrm{m}$. (b) Indirect IF image of Rio1 (anti-Rio1) and nucleolar marker Nop1 (anti-Nop1) in a spread nucleus isolated from a G1 cell. Scale bar, $5 \mu \mathrm{m}$. (c) Nuclear 6 myc-Rio1 and Nop1 levels (normalized to Nop1 concentrations in G1) measured from IF images (anti-myc, anti-Nop1) of spread nuclei isolated from cells progressing through the cell cycle. Error bars, s.d.'s, $n=50$ per time point. (d) Intranuclear distribution of 6 myc-Rio1 established from IF images of spread nuclei isolated from cells synchronously progressing through the cell cycle (from the experiment depicted in $\mathbf{c}$ ). $n=50$ Per time point. (e) 6 myc-Rio1 protein levels at the rDNA as quantified by ChIP-qPCR analysis of cells arrested in G1, $S$ phase, metaphase (M) or anaphase (A). Positions of the real-time qPCR probes along the rDNA unit are indicated (1-5). IGS, intergenic spacer region; RFB, replication fork barrier; rARS, origin of replication; $5 S$ and 35S, genes encoding $5 S$ and $35 S$ rRNA, respectively. The upper plot shows the data obtained with each probe per cell cycle stage (each data point corresponds to the probe indicated above). Error bars, s.d.'s. $n=3$. The lower plot shows the averages of the values obtained with the five probes. (f) Western blot of endogenous 6 myc-Rio1 protein levels (anti-myc) through the cell cycle (Pgk1=loading control). (g) The Rio1 interactome. Rio1 interactors reported in the literature $\left[{ }^{\circ}\right]^{25}$ and identified in this study $\left[{ }^{\star}\right]$ ).

shortened lifespan in yeast ${ }^{29,30}$. Various proteins contribute to sister rDNA alignment and faithful recombination, as described in Supplementary Fig. 1. They include Fob1, Tof2, RENT (Cfil, Cdc14, Sir2), Sgs1, and the monopolin, cohesin and condensin complexes.

To determine the basis for the cell cycle-stage-dependent localization of Riol to the rDNA, we probed Riol recruitment by IF analysis of spread nuclei isolated from mutants lacking one of the above rDNA factors. Cells were released from G1 or S phase (a sir $2 \Delta$ mutant does not respond to $\alpha$-factor) and then tracked through the cell cycle by analysis of spindle morphology (antiTub1 IF) and DNA content (fluorescence-activated cell sorting, FACS) (Supplementary Fig. 3). In short, we found that Rio1 localization to rDNA in interphase depended on Fob1, Sgs1, Sir2 and Cdc14, while its anaphase recruitment required Fob1, Sgs1, monopolin and condensin (Fig. 2a,b and Supplementary Fig. 4a). Riol thus localizes to the rDNA at different cell cycle stages via distinct rDNA factors (summarized in Fig. 2c). The observed changes in Riol recruitment in the mutant backgrounds were not due to alterations in Riol expression or stability, as western blot analyses showed that Rio1 protein levels remained constant through the cell cycle in all of the mutants tested (Supplementary Fig. 4b). Noteworthy, the phosphatase Cdc14 is kept inactive in the nucleolus from G1 through metaphase by its inhibitor Cfil (ref. 31) and becomes released (activated) at anaphase entry. However, when we inactivated and delocalized Cdc14 in G1 

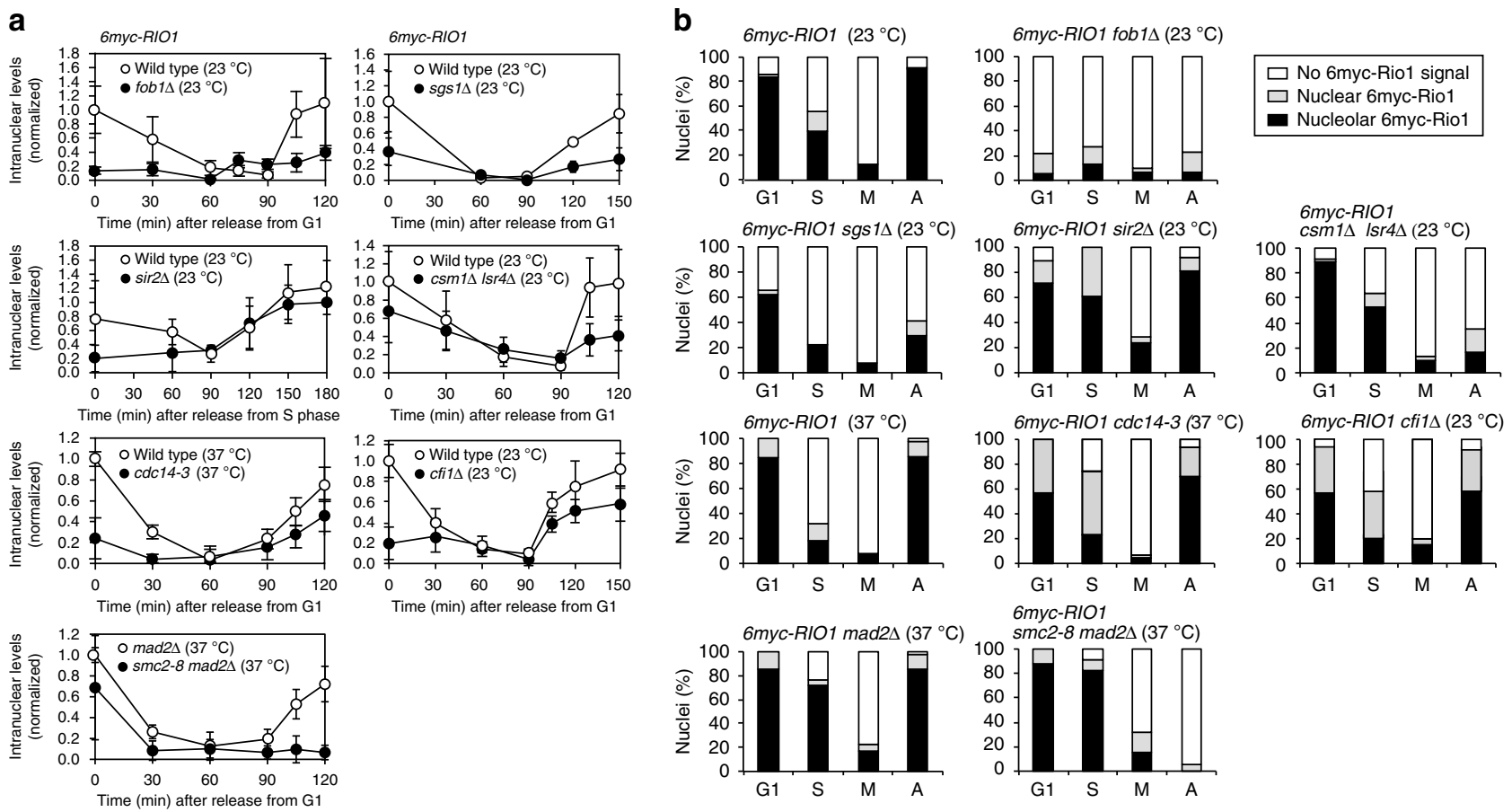

C

Interphase

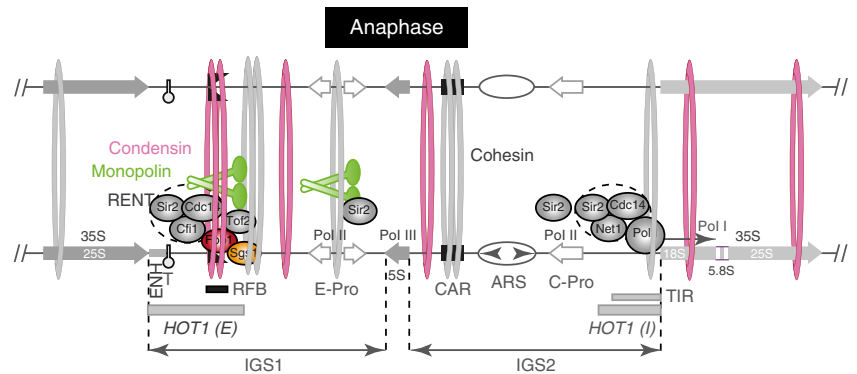

Figure 2 | Distinct sets of nucleolar proteins recruit Rio1 to interphase and anaphase rDNA. (a) Nuclear levels of $6 \mathrm{myc}$-Rio1 through the cell cycle of strains mutated in a single rDNA regulator as determined by quantitative IF imaging (anti-myc) of spread nuclei. Signals are normalized to the $6 \mathrm{myc}$-Rio1 levels measured in the wild-type control strains in G1. Error bars, s.d.'s. $n=50$ Per time point. (b) Intranuclear distribution of $6 \mathrm{myc}$-Rio1 in specific cell cycle stages $(n=50)$ as probed by IF imaging of spread nuclei isolated from the cells in $\mathbf{a}$. (c) Graphic representation of the rDNA factors (coloured) that recruit Rio1 to rDNA in interphase (left) and anaphase (right).

(cdc14-3 mutant at the non-permissive temperature), we observed a marked reduction in Riol levels at interphase nucleoli and, in parallel, a distribution of the kinase throughout the nucleus (Fig. 2b). A constitutive release of $\mathrm{Cdc14}$ instigated by removing Cfil (cfild) confirmed this observation. Hence, albeit anchored in the nucleolus, Cdc14 serves at least to recruit Riol to interphase rDNA.

Characterization of a Riol nuclear depletion mutant. To study Riol activity at the rDNA, we wished to inducibly remove the kinase from the nucleus only. Based on the observation that Riol shuttles between the nucleus and the cytoplasm ${ }^{16}$, we figured that conditionally removing its C-terminal tail containing a putative nuclear localization signal (NLS; Supplementary Fig. 5a) would prevent truncated Riol from entering the nucleus. Riol present in the nucleus at the moment of truncation should still be able to exit from the nucleus as its putative nuclear exit signal localizes at the outer edge of the RIO domain (Fig. 3a and Supplementary Fig. 5b). To allow for conditional truncation, we cloned the Tobacco Etch Virus (TEV) Protease with a C-terminal NLS under control of the galactose-inducible $P_{\text {GAL10 }}$ promoter on a highcopy plasmid (next named $\mathrm{p} P_{G A L 10^{-}}$TEV Protease; Supplementary
Fig. 5c). Next, we introduced a TEV Protease cleavage site just upstream of the NLS in 6myc-Riol (next referred to as 6mycRio1 ${ }^{\text {TEV }}$; Fig. 3a). To confirm the TEV Protease-induced cleavage of 6 myc-Rio $^{\mathrm{TEV}}$, we grew the $6 \mathrm{myc}^{-r i o 1^{T E V}}$ strains carrying $\mathrm{p} P_{G A L 10}-T E V$ Protease or the empty $\mathrm{p} P_{G A L 10}$ vector (negative control) in $2 \%$ raffinose medium and then treated the cells for $1 \mathrm{~h}$ with $2 \%$ galactose. TEV Protease expression led to the removal of 6myc-Riol's C-terminal 78 residues (Fig. 3b), as indicated by anti-myc western blot analysis. Within the hour, truncated 6 mycRio $1^{\text {TEV }}$ had also become depleted from the nucleus as shown by IF microscopy of spread nuclei (Fig. 3c) and whole cells (Fig. 3d). Whereas $6 \mathrm{myc}^{-R i o} 1^{\mathrm{TEV}}$ was no longer detected in the nucleus, its signals could still be observed and quantified in the cytoplasm (Fig. 3d). When plated on 2\% galactose medium, the mutant strain died, indicating that the C-terminal region of Riol is essential for viability, in agreement with previous observations ${ }^{12}$. Importantly, overexpressing the TEV Protease in wild-type yeast did not affect viability (Fig. 4a).

To determine whether truncated Riol remains a functioning kinase, we measured the kinase activity of full-length and cleaved 6myc-Rio ${ }^{\text {TEV }}$. We synchronized the 6 myc-rio ${ }^{\text {TEV }} \mathrm{p} P_{G A L 10^{-T E V}}$ Protease and 6 myc-rio $1^{T E V} \mathrm{pP}_{\text {GAL10 }}$ strains in G1 and induced TEV Protease expression with $2 \%$ galactose $(1 \mathrm{~h})$ while keeping 
a
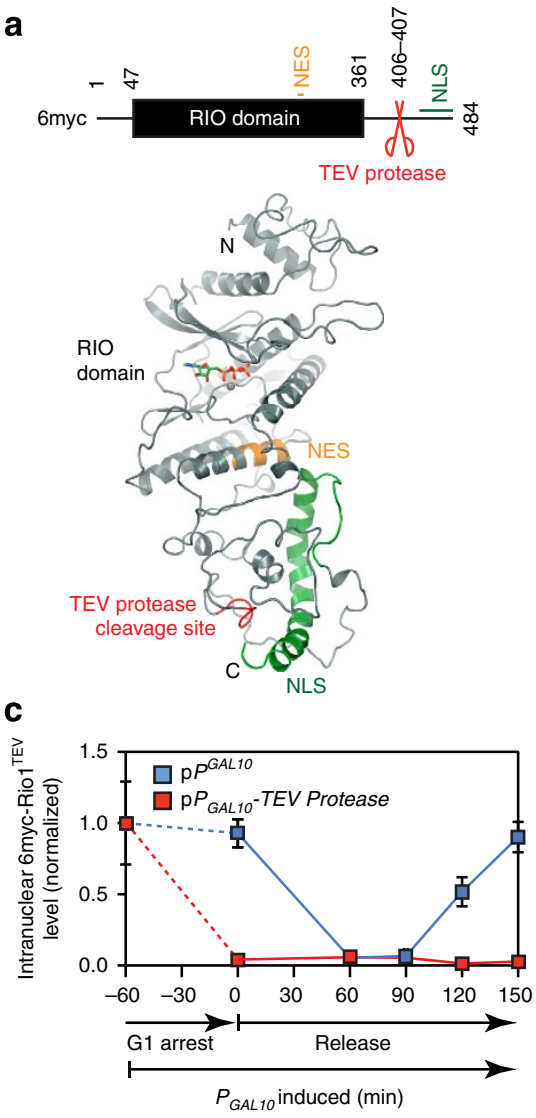

b
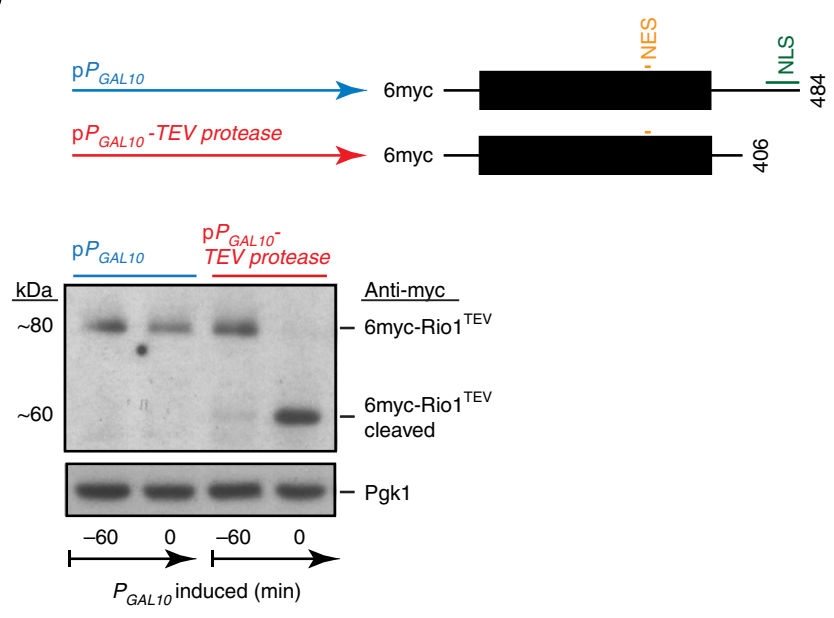

6myc-rio $1^{\text {TEV }} \mathrm{p} P_{\text {GAL10 }}$
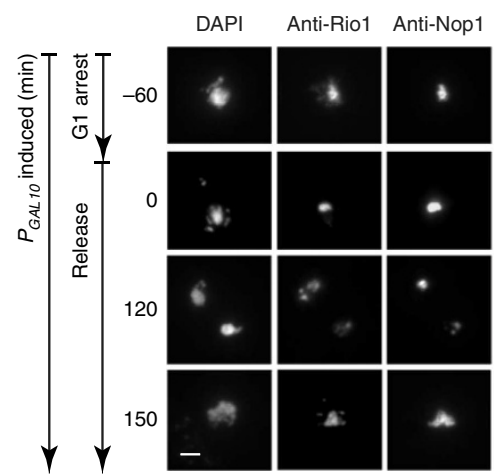

Merge

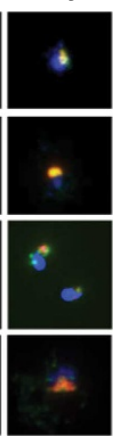

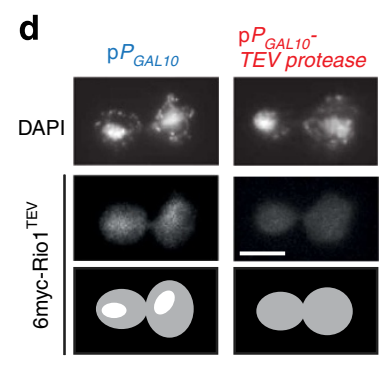

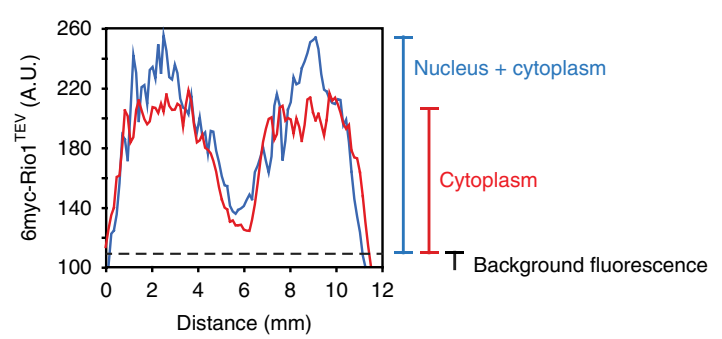

Figure 3 | Depletion of Rio1 from the nucleus. (a) The Rio1 nuclear depletion construct. To-scale representation and computational model of the 6 mycRio1 ${ }^{\text {TEV }}$ protein. The RIO domain, the putative nuclear export signal (NES), the putative NLS and the TEV Protease cleavage site (introduced between E406 and E407) are indicated. The model of full-length 6myc-Rio1 TEV bound to ATP and manganese was generated with Phyre2 (http://www.sbg.bio.ic.ac.uk/ phyre2) based on the structure of $A$. fulgidus Rio1 (PDB 1ZTH) ${ }^{45}$. (b) Ectopic expression of the TEV Protease truncates the 6 myc-Rio1 ${ }^{T E V}$ protein at its

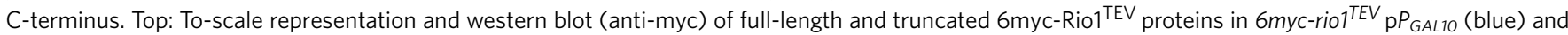
6myc-rio1 ${ }^{T E V}$ p $P_{G A L 10}$-TEV Protease (red) cells before and after $P_{\text {GAL10 }}$ induction with $2 \%$ galactose (Pgk1, loading control). (c) Intranuclear 6 myc-Rio1 ${ }^{T E V}$ levels in cells lacking (blue) or expressing (red) TEV Protease, quantified from IF images (anti-myc) of spread nuclei. Both strains were grown in $2 \%$ raffinose medium and arrested in G1. $P_{\text {GAL10 }}$ was induced ( $1 \mathrm{~h}, 2 \%$ galactose), and the cells then released into the cell cycle ( $2 \%$ galactose medium, $150 \mathrm{~min}$ ). $n=50$ Per time point. Error bars, s.d.'s. Representative images are shown on the right. Scale bar, $5 \mu \mathrm{m}$. (d) IF images of $6 \mathrm{myc}$-Rio1 ${ }^{\mathrm{TEV}}$ (anti-myc) in anaphase-arrested cdc15-2 yeast cells that lack (left, blue) or express (right, red) TEV Protease (DAPI=DNA). Scale bar, $5 \mu \mathrm{m}$. Fluorescence levels were quantified along the horizontal axes.

the cells arrested in G1. Next, we released the cells in $2 \%$ galactose medium and took samples $1 \mathrm{~h}$ before, upon and $3 \mathrm{~h}$ after the release. Western blot analysis confirmed the $\mathrm{C}$-terminal truncation of $6 \mathrm{myc}^{-R i o 1^{\mathrm{TEV}}}$ in the strain expressing TEV Protease (Fig. 4b). Full-length and truncated 6myc-Riol ${ }^{\text {TEV }}$ were then immunopurified (anti-myc beads) and their activity assayed on dephosphorylated casein ${ }^{21}$. The measured kinase activities were identical (Fig. 4b), confirming an earlier report that recombinant Rio1 lacking a similar C-terminal region is still active as a kinase in vitro ${ }^{22}$. To exclude a possible contribution from casein kinases CK1 and CK2, shown to co-purify with full-length Rio1 (refs 12,22) and with Rio1 lacking its C-terminal 46 residues ${ }^{9}$, the assay was repeated in the presence of CK1 and CK2 inhibitors. While the overall kinase activity decreased, we measured no differences between the kinase activities of fulllength and truncated 6 myc-Rio1 ${ }^{\mathrm{TEV}}$ (Supplementary Fig. 6a).

The $\mathrm{C}$ terminus of Rio1 was previously shown to be necessary for cytoplasmic Riol to bind to the pre-40S ribosome and for promoting $20 \mathrm{~S}$ pre-rRNA maturation ${ }^{12}$. As such, we examined whether truncated $6 \mathrm{myc}^{-R i o 1^{\mathrm{TEV}}}$ could still mediate these functions within the 3-h time frame during which we phenotype the mutant cells (see further down). Specifically, we 


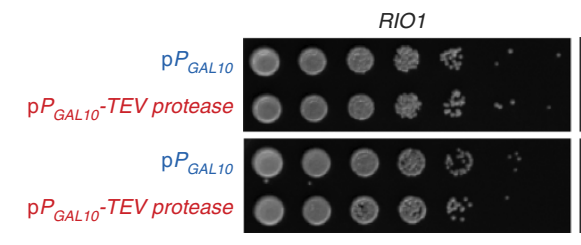

b

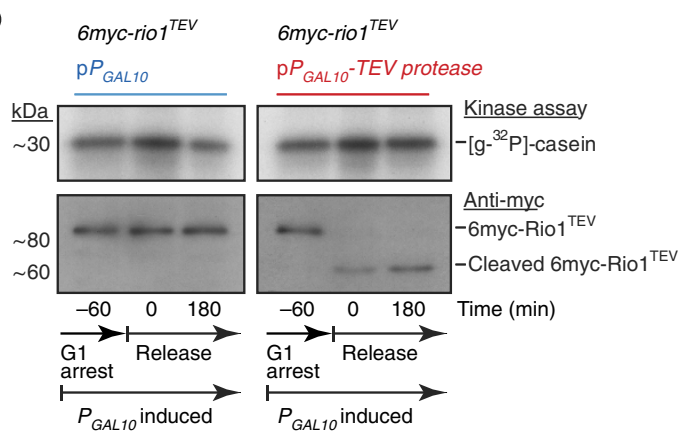

c
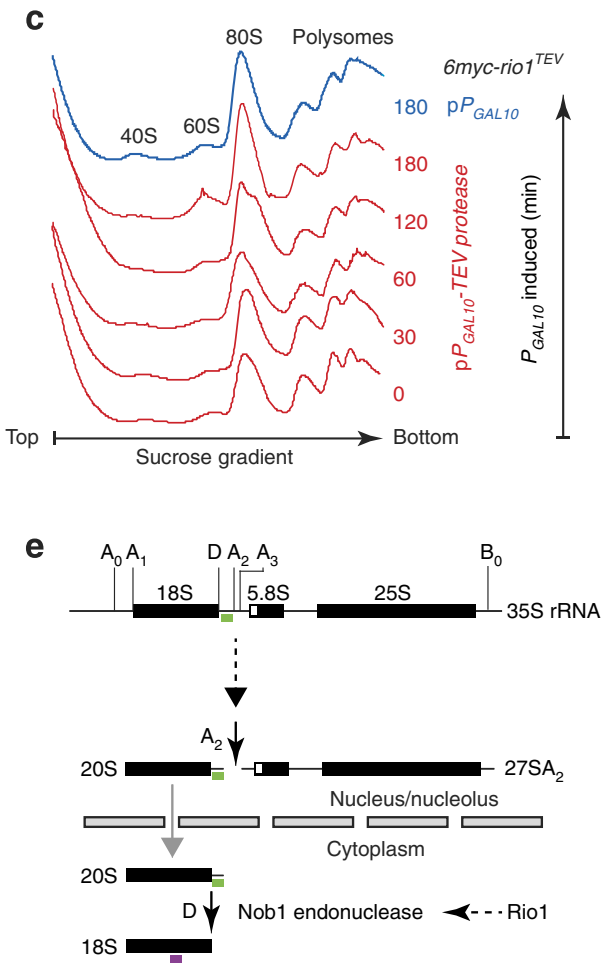

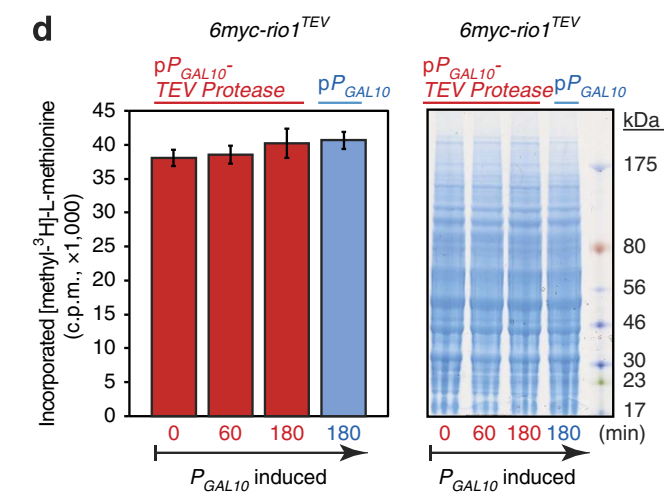

$6 m y c-r i o 1^{T E V}$

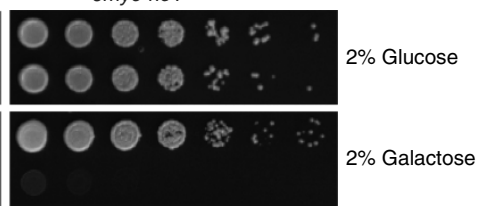

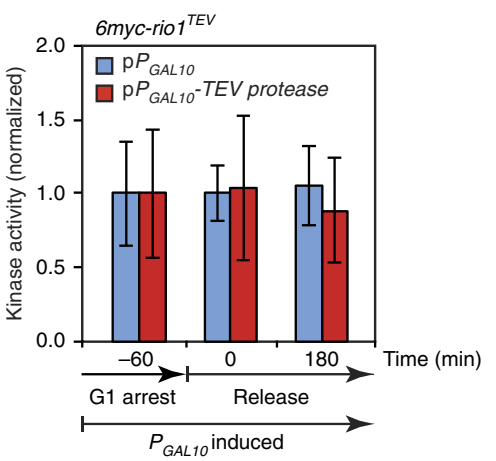

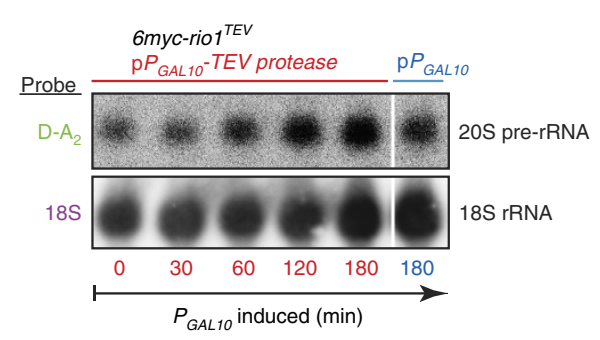

Figure 4 | Functional characterization of the Rio1 nuclear depletion mutant. (a) Growth of the RIO1 and 6myc-rio $1^{T E V}$ strains carrying $\mathrm{p} P_{G A L 10}$ (blue) or

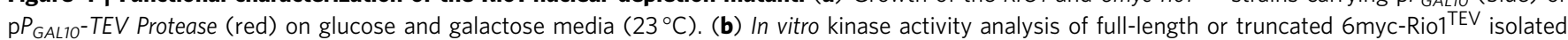
from yeast lacking or expressing TEV Protease, respectively. The reaction contained $\left[\gamma_{-}{ }^{32} \mathrm{P}\right]$ ATP and dephosphorylated casein, as the substrate. Left; top: $\left[\gamma_{-}{ }^{32} \mathrm{P}\right]$-phosphorylated casein visualized radiographically; bottom: western blots (anti-myc) of full-length or truncated $6 \mathrm{myc}-$ Rio1 ${ }^{\mathrm{TEV}}$. The indicated times $(\mathrm{min})$ are relative to the release from G1. Right: 6 myc-Rio1 ${ }^{\mathrm{TEV}}$ kinase activity normalized to the activity measured $1 \mathrm{~h}$ before $P_{G A L 10}$ induction. $n=3$. Error bars, s.d.'s. (c) Ribosome profiles of 6 myc-rio $^{T E V} \mathrm{p} P_{\text {GAL10 }}$ (blue) and 6 myc-rio ${ }^{T E V} \mathrm{pP} P_{G A L 10}$-TEV Protease (red) strains. Samples were taken at the indicated time points and the cell extracts fractionated by $5-45 \%$ sucrose gradient ultracentrifugation. The $254-n m$ absorption profiles measured along the gradients are shown. (d) Cells depleted of nuclear Rio1 activity are not affected in protein neo-synthesis. 6 myc-rio1 $^{T E V} \mathrm{pP} P_{\text {GAL10 }}$ (blue) and 6 myc-rio $^{T E V} \mathrm{pP} P_{\text {GAL10-TEV }}$ Protease cells (red) were grown in $2 \%$ raffinose medium and then treated with $2 \%$ galactose. The cells were provided $\left(20\right.$ min) with [methyl- $\left.{ }^{3} \mathrm{H}\right]-\mathrm{L}_{-}$ methionine and its incorporation in nascent proteins quantified (scintillation counts) at the indicated time points. The numbers represent average values. $n=3$. Error bars $=s$.d's. The extracted proteins were run in parallel on a Nu-PAGE gradient gel and then Coomassie stained, confirming that equal protein amounts were analysed for [methyl- ${ }^{3} \mathrm{H}$ ]-L-methionine incorporation. (e) Northern blots of total RNA isolated from 6 myc-rio $1^{T E V}$ p $P_{\text {GAL10 }}($ blue) and 6 myc-

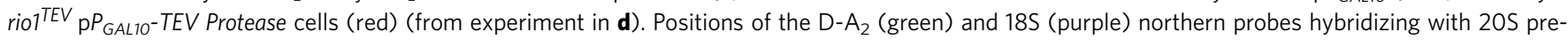
rRNA and $18 \mathrm{~S}$ rRNA are indicated in the sketch on the left. 
probed ribosome biogenesis, protein translation and 20S prerRNA to $18 \mathrm{~S}$ rRNA maturation. Whole-cell extracts from exponentially grown $6 m y c$-rio1 $1^{T E V} \mathrm{pP} P_{G A L 10^{-T E V} \text { Protease and }}$ 6 myc-rio $^{T E V} \mathrm{pP}_{\text {GAL10 }}$ strains were collected at different time points $(0-3 \mathrm{~h})$ after $P_{G A L 10}$ induction. The extracts were fractionated by $5-45 \%$ sucrose gradient ultracentrifugation and their nucleic acid profiles were recorded at $254 \mathrm{~nm}$. We observed a subtle decrease in $40 \mathrm{~S}$ subunits levels (and concomitant increase in $60 \mathrm{~S}$ levels) at the latest time points in the cells depleted of nuclear Riol (Fig. 4c). The ribosome (80S) and polysome profiles of both strains were basically identical suggesting similar mRNA translation capacities. We confirmed this conclusion as pulse labelling of the mutant and control cultures with [methyl $\left.{ }^{3} \mathrm{H}\right]-\mathrm{L}-$ methionine revealed no difference in the amount of radiolabelled methionine that was incorporated in the neo-synthesized proteins (Fig. 4d). Next, we probed cytoplasmic $20 \mathrm{~S}$ pre-rRNA maturation at pre-40S particles via northern blot analysis. In good agreement with our slight decrease in $40 \mathrm{~S}$ levels, we observed a mild $20 \mathrm{~S}$ prerRNA to $18 \mathrm{~S}$ rRNA processing defect (Fig. 4e). Because our data show that during the short time frame of one cell cycle $(3 \mathrm{~h})$, the cytoplasmic activity of truncated 6 myc-Rio $1^{\text {TEV }}$ is not markedly affected, we used this mutant to study how activities at the rDNA are affected in yeast depleted of nuclear Riol.

Riol promotes rDNA stability and segregation. To phenotype the Riol nuclear exclusion mutant, we first analysed its progression through the cell cycle. Compared with the control cells, yeast depleted of nuclear Riol consistently showed a 15-20-min delay in cell cycle commencement at START (G1/S transition; orange triangles in Fig. 5a), whereas progression through the subsequent cell cycle stages was not affected. Importantly, overproduction of the TEV Protease in a wild-type strain did not delay cell cycle initiation (Supplementary Fig. 6b). IF microscopy of spread nuclei revealed nucleolar fragmentation in the absence of Riol (Fig. 5b), an anomaly that is indicative of rDNA instability. To probe this phenotype further, we grew the 6mycrio $1^{T E V} \mathrm{p} P_{G A L 10^{-T E V ~ P r o t e a s e ~ a n d ~} 6 \text { myc-riol } 1^{T E V}} \mathrm{p} P_{\text {GAL10 }}$ strains for eight divisions in $2 \%$ galactose medium. Electrophoretic analysis of their DNA content followed by Southern blot analysis with a $25 \mathrm{~S}$ rDNA probe ${ }^{32}$ revealed ERCs and an expanded rDNA array, as in a sir $2 \Delta$ mutant (positive control; Fig. $5 \mathrm{c}$ ), known to contain 200-300 rDNA units ${ }^{33}$. Homologous recombinations underlaid these rDNA-instability phenotypes as GFP-labelled recombination mediator Rad52 formed fluorescent foci at the nucleolar periphery, the area where rDNA recombination takes place $^{34}$ (Fig. 5d). Despite the rDNA hyper-recombination events, progression through $\mathrm{S}$ phase was not delayed (Fig. 5a) and the DNA damage checkpoint kinase Rad53 not activated/ phosphorylated $^{35}$ (Fig. 5e). Importantly, the cells depleted of nuclear Riol were DNA checkpoint proficient as they arrested in $S$ phase with phosphorylated Rad53 upon treatment with hydroxyurea (Fig. 5f and Supplementary Fig. 6c).

Through IF microscopy analysis of isolated nuclei, we next probed which rDNA regulators required nuclear Riol activity for their localization through the cell cycle. In short, cells lacking nuclear Rio1 had reduced levels of Sir2 at rDNA in interphase and metaphase, and of condensin in anaphase. The inability of these proteins to localize to the nucleolus led to their diffusion throughout the nucleus (Fig. 5g, and Supplementary Figs 7 and 8). Reduced Sir2-mediated silencing of rDNA transcription ${ }^{36,37}$, required for sister rDNA alignment, may explain the observed rDNA-instability and array-expansion phenotype in yeast lacking nuclear Riol activity. As for condensin, this complex becomes highly enriched at anaphase rDNA to compact the array. Indeed, the large rDNA locus must be condensed before chromosome XII can move through the bud neck into the daughter cell ${ }^{2}$. In addition, condensin recruits topoisomerase II that resolves the remnant catenates lingering between the sister rDNA loci ${ }^{2-4,7}$. Both condensin-driven activities promote rDNA segregation in late anaphase. Indeed, live-cell microscopy revealed that yeast depleted of nuclear Riol was severely affected in its ability to segregate its GFP-marked rDNA loci (Fig. 6a). In contrast, centromere segregation was not affected (Supplementary Fig. 9a). Noteworthy, in cells lacking nuclear Rio1, the anaphase spindle (identified by mCherry-Tub1) extended till $11 \mu \mathrm{m}$ (versus $7 \mu \mathrm{m}$ in the control strain; Fig. 6a), likely to try and segregate the rDNA loci. This phenotype is consistent with a defect in rDNA condensation $^{3}$.

Riol downregulates PolI and stimulates pre-rRNA processing. For rDNA to condensate and segregate, yeast must turn down Poll activity and locally resolve its transcripts before condensin can be loaded ${ }^{1,4}$. The Cdc14 phosphatase was previously shown to downregulate PolI in anaphase ${ }^{4}$. We wondered whether also Riol reduces Poll activity since our ChIP-qPCR analyses had identified high levels of 6 myc-Riol at the $35 \mathrm{~S}$ promoter and gene sequence in anaphase cells ( $c d c 15-2)$ (probes 4 and 5; Fig. 1e). As such, we arrested the 6 myc-Riol $^{\text {TEV }}$ cells in anaphase (cdc15-2) following depletion of nuclear Riol activity at the metaphaseanaphase transition. RT-qPCR analysis of cDNA with a $5^{\prime}$-external transcribed spacer $\left(5^{\prime} \mathrm{ETS}\right)$ probe (probe 4 in Fig. 6b) revealed a threefold increase in $35 \mathrm{~S}$ rRNA levels, as compared with the control anaphase cells. This result was confirmed by northern blot hybridization with a $+1-\mathrm{A}_{0}$ probe showing a 2.5 -fold increase in 35S rRNA concentrations (Fig. 6b), suggesting that Riol downregulates PolI activity in anaphase. To corroborate this conclusion, we localized PolI by ChIP-qPCR analysis of its subunit Rpa43 in anaphase-arrested $c d c 15-2$ cells $\left(37^{\circ} \mathrm{C}\right)$ lacking or containing nuclear Riol activity. In the anaphase control cells, Rpa43 levels at the $35 \mathrm{~S}$ promoter and gene sequence were low but increased by five- and eightfold, respectively, in the absence of nuclear Riol activity (red bars, Fig. 6c). Combined, our Poll transcription and localization data indicate that Riol downregulates Poll activity in anaphase. The Cdc14 phosphatase reduces PolI activity by dissociating PolI from the anaphase $\mathrm{rDNA}^{4}$. Our Rpa43 ChIP data show an accumulation of PolI at the 35S unit in the absence of nuclear Riol activity, suggesting that Rio1 represses PolI transcription in a similar fashion.

Since both the Cdc14 phosphatase ${ }^{4}$ and Riol kinase downregulate PolI in anaphase, we next probed their relative contributions to this process. Whereas anaphase-arrested cells lacking Riol activity were characterized by a threefold increase in $35 \mathrm{~S}$ rRNA concentrations (Fig. 5b, probe 4), anaphase cells lacking Cdc14 activity ( $c d c 14-3)$ harboured only a 1.5 -fold increase in $35 \mathrm{~S}$ transcript levels as compared with $c d c 15-2$ control cells (Fig. 6d), confirming previous findings ${ }^{4}$. Removing both Cdc14 and Riol activities led to a fourfold increase, indicating that both enzymes repress in parallel PolI transcription in anaphase.

As Rio1 localizes to rDNA also before anaphase (Fig. 1c-e) and as PolI transcribes rDNA from G1 through metaphase ${ }^{4}$, we wondered whether Riol also modulates PolI transcription before anaphase. To answer this question, we arrested 6 myc-rio $1^{T E V}$ $\mathrm{p} P_{G A L 10}-T E V$ Protease and 6myc-rio $1^{T E V} \mathrm{pP} P_{G A L 10}$ control cells in G1, depleted the cells of nuclear Riol activity and synchronously released them into the cell cycle. Variations in $35 \mathrm{~S}$ transcript levels measured with the $5^{\prime}$ ETS RT-qPCR probe were rather small in the control cells (low in $\mathrm{S}$ phase, slight increase in metaphase and slight decrease in anaphase; Fig. 7a and Supplementary Fig. 9b). In 
a

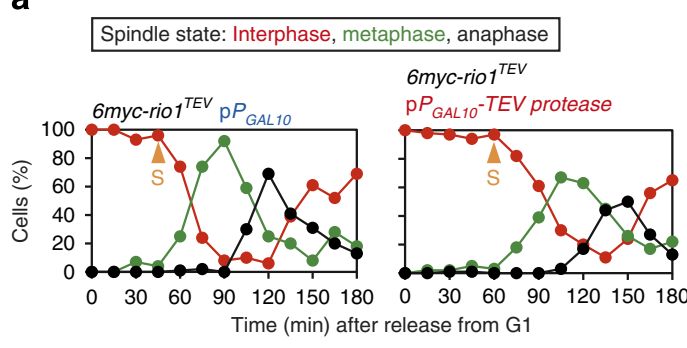

C

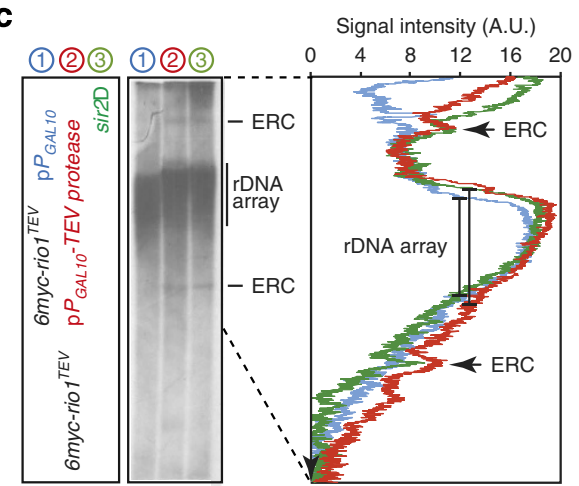

e
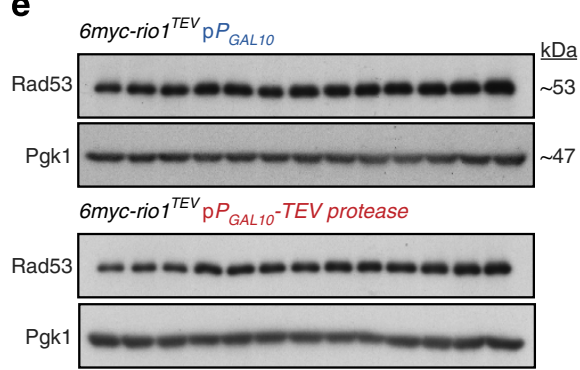

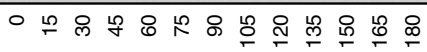

Time ( $\mathrm{min}$ ) after release from $\mathrm{G} 1$

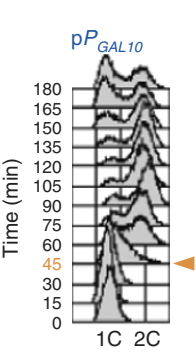

$\mathrm{p} P_{\text {GAL } 10^{-}}$

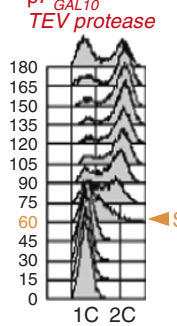

d

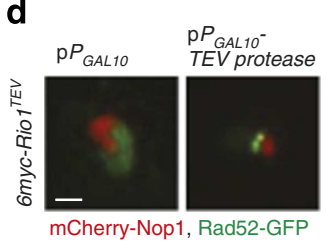

\section{f}

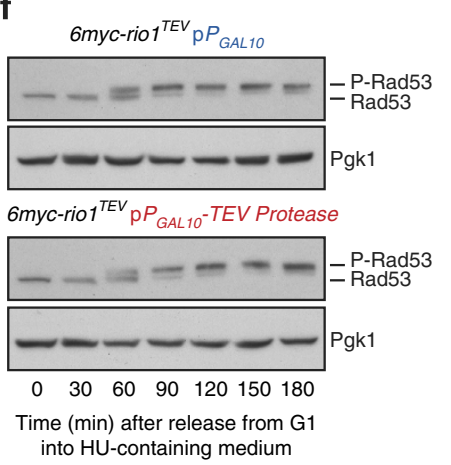

b

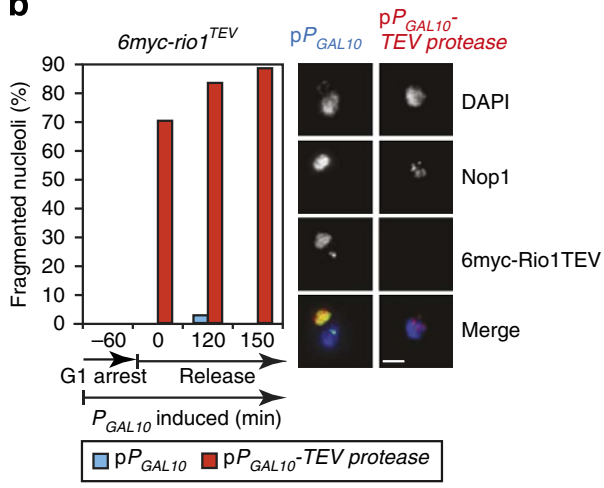

g
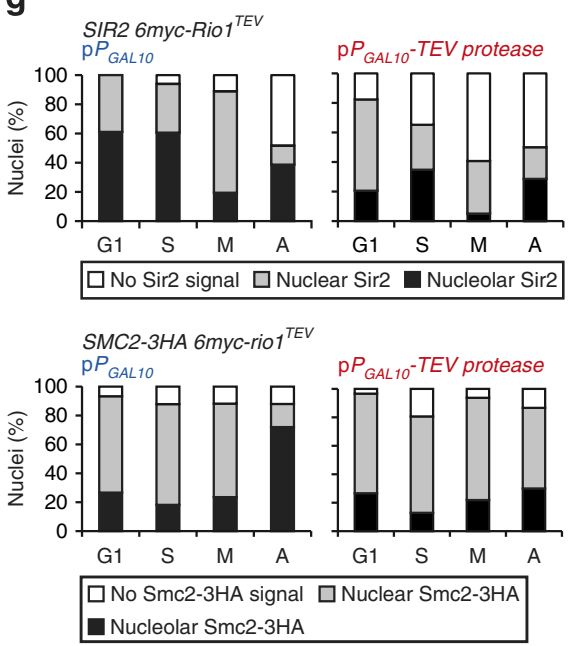

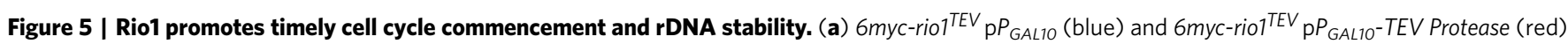
cells were arrested in $\mathrm{G} 1$ ( $2 \%$ raffinose). $P_{\text {GAL10 }}$ was then induced ( $1 \mathrm{~h}, 2 \%$ galactose) and the cells released into the cell cycle ( $2 \%$ galactose medium). Cells were tracked by analysis of spindle morphology (anti-Tub1 IF; $n=200$ cells per time point) and DNA content (FACS). The orange arrows indicate $S$ phase.

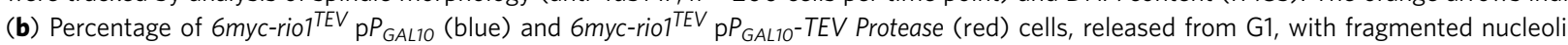
(Nop1 = nucleolar marker), as established by IF imaging analysis of spread nuclei (anti-myc, anti-Nop1). $n=50$ Per time point. Representative IF images are shown on the right. Scale bar, $5 \mu \mathrm{m}$. (c) Left: Southern blot (anti-25S) of total DNA isolated from 6myc-rio1 ${ }^{\text {TEV }} \mathrm{pP}_{\text {GAL10 }}$ (blue), 6myc-rioT TEV $\mathrm{pP}$ GAL10-TEV Protease (red) and sir2 $\Delta$ cells (green) grown for eight divisions in $2 \%$ galactose medium. The rDNA array and ERCs are indicated. Right: quantified

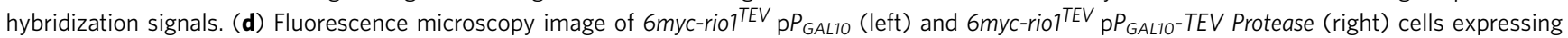
Rad52-GFP and mCherry-Nop1. Scale bar, $5 \mu \mathrm{m}$. (e) Western blots of DNA checkpoint kinase Rad53 (anti-Rad53; anti-Pgk1=loading control) in 6mycrio1 $^{\text {TEV }} \mathrm{pP} P_{\text {GAL1O }}$ (blue) and 6myc-rio TEV ${ }_{\mathrm{pP}} \mathrm{GAL1O}$-TEV Protease (red) cells released from G1 in 2\% galactose medium. (f) Western blots of Rad53 (anti-Rad53, anti-Pgk1 = loading control) in 6myc-rio TEV $\mathrm{pP}_{\text {GAL10 }}$ (blue) and 6myc-rio1 ${ }^{\text {TEV }} \mathrm{p} P_{\text {GAL10 }}$-TEV Protease (red) cells released from G1 in $2 \%$ galactose medium containing hydroxyurea. (g) Intranuclear distribution of Sir2 and condensin (subunit Smc2-3HA) as determined by IF imaging of spread nuclei (anti-Sir2 and anti-HA, respectively) isolated from of 6 myc-rio $^{T E V} \mathrm{p} P_{\text {GAL10 }}$ and 6 myc-rio ${ }^{T E V} \mathrm{pP} \mathrm{FAL10}$-TEV Protease cells released from G1 into the cell cycle (2\% galactose medium). $n=50$ Per analysis.

contrast, marked changes were observed in the cells depleted of nuclear Rio1. Primary transcript levels were sevenfold elevated in G1, then decreased through S phase (still 3.5-fold above the levels measured in the $S$ phase control cells) and increased threefold in anaphase. This transcript-concentration profile is consistent with Riol localizing to the rDNA (Fig. 1c-e) to reduce Poll activity through the cell cycle.

To ensure rDNA segregation, yeast must not only reduce PolI activity but also locally resolve the PolI-generated transcripts. During our earlier northern blot analysis of 20S pre-rRNA processing in exponential cells depleted for $3 \mathrm{~h}$ of nuclear Rio1 activity (D-A $A_{2}$ probe in Fig. $4 \mathrm{e}$ ), we had noticed that the cells accumulated 32S rRNA transcripts (Supplementary Fig. 9d), indicating a defect in $32 \mathrm{~S}$ cleavage at $\mathrm{A}_{2}$ by the nucleolar SSU processome and associated factors ${ }^{5,38-40}$. As such, we probed rRNA transcript processing in our anaphase-arrested cells (cdc15-2) depleted of Rio1 activity. Northern hybridization of total rRNA with an $\mathrm{A}_{2}-\mathrm{A}_{3}$ probe revealed a 2.5-fold increase in $35 \mathrm{~S}$ and $32 \mathrm{~S}$ pre-RNA levels (Fig. 7b), indicating a derepressed Poll activity and a defect in nascent transcript processing at $\mathrm{A}_{2}$. To determine whether the accumulation of pre-rRNA impaired rDNA segregation in yeast depleted of nuclear Riol, we tracked rDNA-GFP through anaphase in $6 m y c-r i o 1^{T E V}$ $\mathrm{p} P_{G A L 10}$ and $6 m y c-r i o 1^{T E V} \mathrm{p} P_{G A L 10^{-T E V}}$ Protease cells that 
inducibly expressed the Aspergillus oryzae ribonuclease RntA ${ }^{4,41}$ from $P_{G A L 1}$ (Fig. 7c). We observed that the RntAmediated degradation of the accumulated rRNA transcripts (Supplementary Fig. 9e) promoted rDNA segregation in yeast depleted of nuclear Riol (Fig. 7c). As such, rDNA transmission occurs only when Rio1, together with Cdc14, downregulates PolI activity and then stimulates the co-transcriptional processing of nascent transcripts in the nucleolus.

a
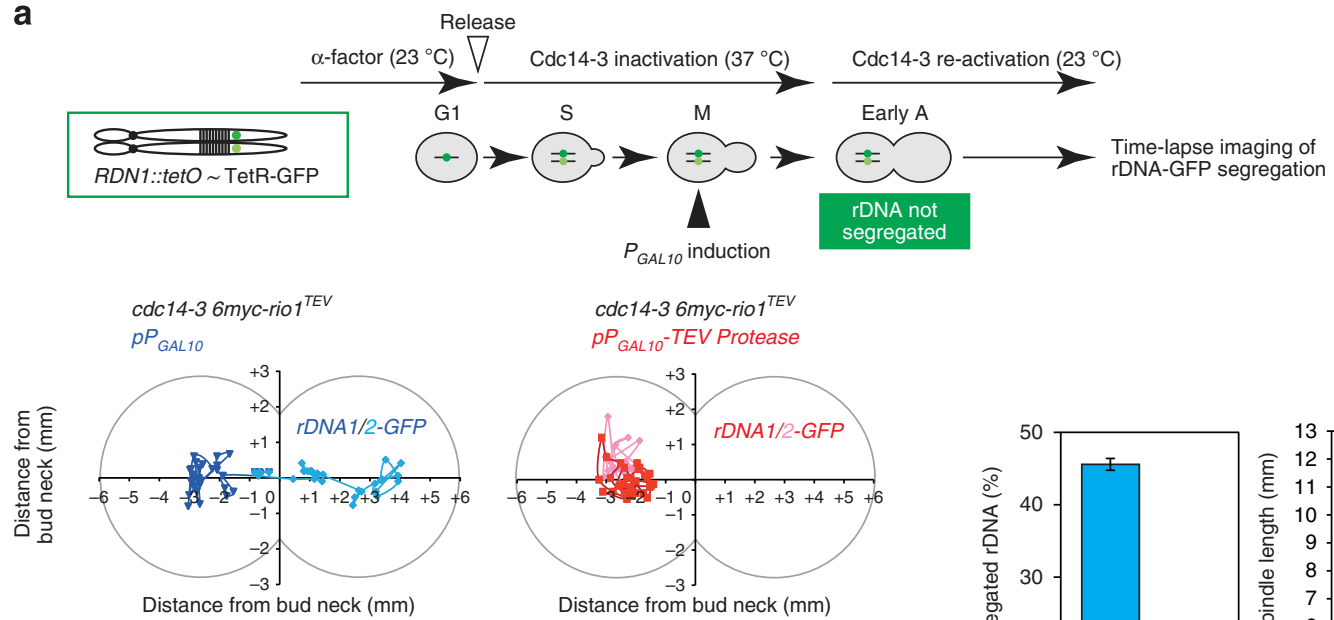

cdc14-3 6myc-rio $1^{\text {TEV }}$

PP $P_{\text {GAL10 }}$-TEV Protease
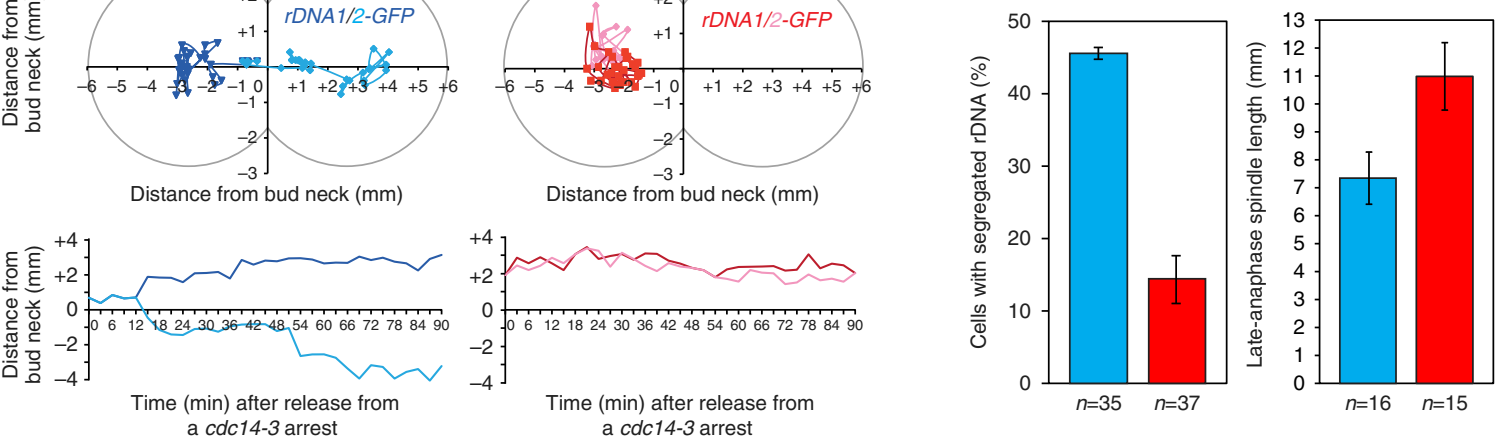

b
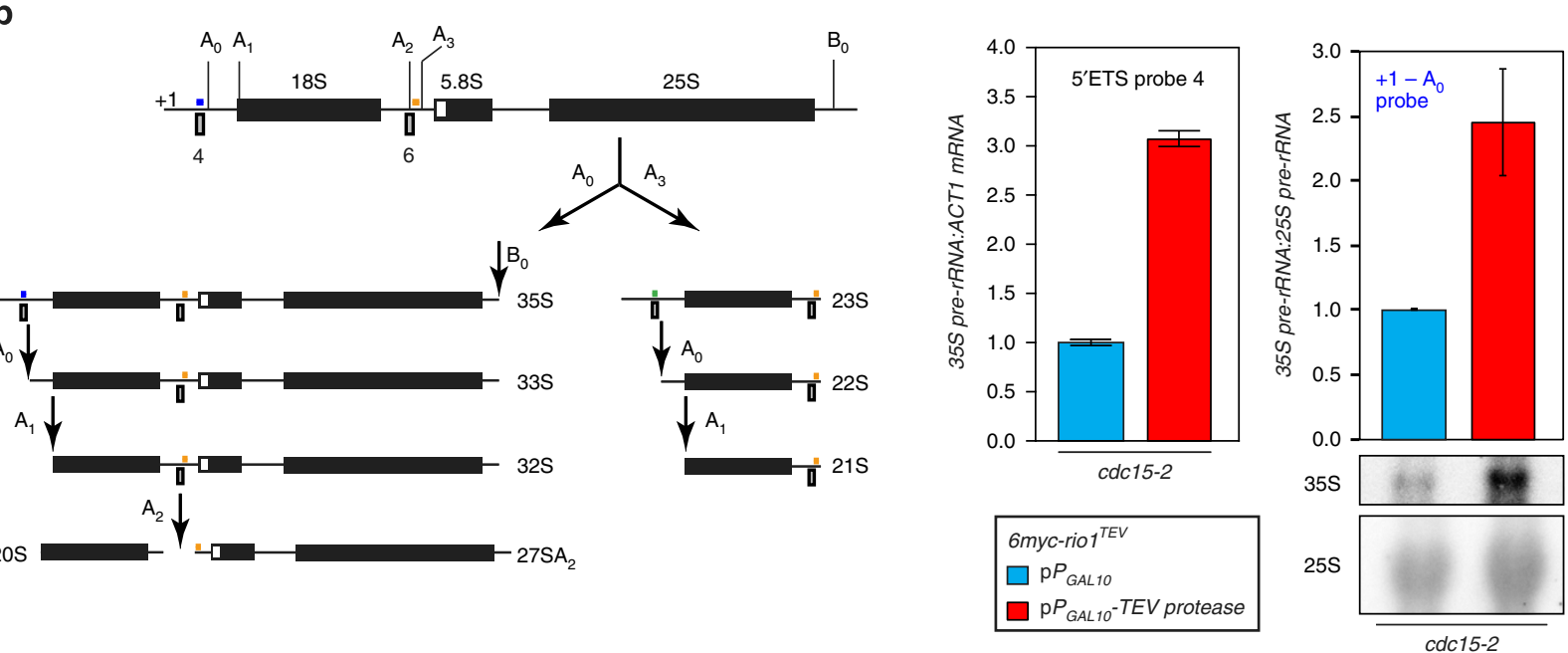

C

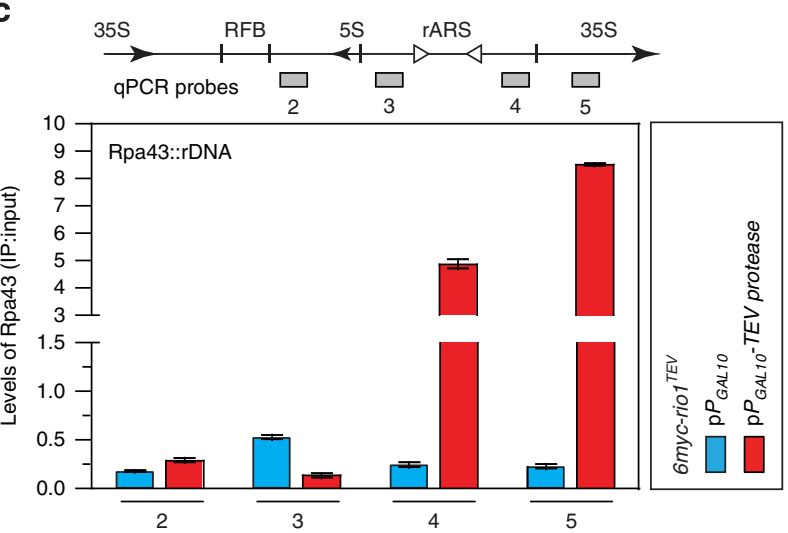

d

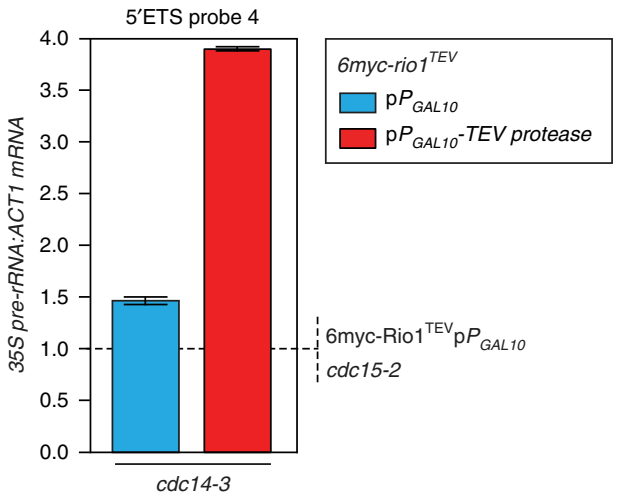


Riol reduces PolI activity by targeting subunit Rpa43. Transcription factor Rrn3 recruits PolI to the 35 S promoter via PolI subunit Rpa43, an event that converts inactive PolI into an initiation-competent PolI (ref 42,43). In anaphase, the Cdc14 phosphatase downregulates PolI by dephosphorylating Rpa43, resulting in PolI dissociating from the anaphase rDNA ${ }^{4}$. To examine whether Riol also dislodges Poll by targeting Rpa43, we first probed their physical interaction and found that 6myc-Rio1 and Rpa43-3HA efficiently co-immunoprecipitated from exponentially growing cells (Fig. 8a). Next, PhosTag western blot analysis of Rpa43-3HA in 6myc-rio1 ${ }^{T E V} \mathrm{pP} P_{\text {GAL10 }}-T E V$ Protease and 6 myc-rio1 ${ }^{\text {TEV }} \mathrm{p} P_{\text {GAL10 }}$ cells identified a slowmigrating, anaphase-specific Rpa43-3HA phospho species that was absent in the cells lacking nuclear Riol activity (Fig. 8b). To further associate this anaphase-specific Rpa43 phospho species with Rio1 kinase activity, we analysed Rpa43 phosphorylation in cells expressing either a dominant-negative kinase-dead rio1 allele $\left(P_{G A L 1}\right.$-rio1 $\left.^{\text {D244A }}\right)$ or wild-type RIO1 ( $P_{G A L 1}$-RIO1) (ref. 12). PhosTag western blot analysis showed that the cells expressing rio1 ${ }^{D 244 A}$ lacked the slow-migrating Rpa43-3HA phospho species in anaphase (Fig. 8c). To examine whether Riol directly phosphorylates Rpa43, we performed an in vitro kinase assay with recombinant His6-Riol and Rpa43-His6-HA purified from Escherichia coli (Supplementary Fig. 9f) and found that Rpa43 was phosphorylated only in the presence of Rio1 (Fig. 8d). Interestingly, Rio1 autophosphorylation ${ }^{12,22}$ was threefold $(3.1 \pm 0.6)$ higher in the presence of Rpa43, indicating that Rio1 binding to Rpa43 may have stimulated its own phosphorylation, which in turn may have promoted the phosphorylation of Rpa43 (the protein loading controls for the kinase assay are shown in Supplementary Fig. 9g). Finally, we sought to identify the Rpa43 residues targeted by Riol using mass spectrometry. After repeating the in vitro kinase assay in the presence and absence of unlabelled ATP, nanoLC-MS/MS analysis ${ }^{44}$ (98.8\% combined peptide coverage) found Rpa43 phospho-peptide QHLNPLV MKY73NNK to be threefold (3.2 \pm 0.3$)$ enriched over the negative-control peptide (unphosphorylated peptides were 1.1to 1.3-fold upregulated versus their counterparts in the negativecontrol Rpa43 species; Fig. 8e). Tyrosine 73 was the sole Rpa43 residue found to be phosphorylated. Although no physiological substrates of Riol have yet been identified, Riol kinases are considered serine kinases as Archeoglobus fulgidus Riol phosphorylates itself at S108 (ref. 45) and because S. cerevisiae Rio1 phosphorylates serines in casein and in itself (residues not identified $)^{21}$. However, recent studies suggested that RIO kinases can perform autophosphorylation at aspartate ${ }^{12,13}$, within the RIO domain. Our findings further indicate that Rio1 phosphorylation activity is wide ranging and may harbour serine/tyrosine dual specificity, as observed for canonical kinases CK2 (refs 46,47), Hrr25 (ref. 48), Mps1 (ref. 49), Rad53 (ref. 50), Dusty ${ }^{51}$ and Swel (ref. 52). Tyrosine 73 is one of the few evolutionary conserved residues present in Rpa43 (Fig. 8f and Supplementary Fig. 10) and resides-from a regulatory point of view-at a highly strategic position. Indeed, within Rpa43, Y73 lies in a short $\mathrm{N}$-terminal $\beta$-strand proximal to six $\mathrm{C}$-terminal $\beta$-strands and one $\alpha$-helix that are enriched with phosphorylated residues, as identified by mass spectrometric analysis of Rpa43 isolated from yeast ${ }^{53-55}$. Y73 flanks K72 and lies near G78 and L87G88Y89, putative interaction points that may mediate Rpa43Rpa14 heterodimer formation within PolI (refs 56,57). In addition, Y73 lies in close proximity to the negatively charged residues emanating from the C-terminus of Rpa135 (Fig. 5g). As such, Riol kinase activity could induce a charge-based repulsion and destablization of protein interactions within the polymerase complex. The N-terminal domain of Rpa43 that harbours Y73 also binds to the Poll-recruiting transcription factor Rrn3 (ref. 53). Taken together, our cell biological and biochemical data indicate that Rio1 phosphorylates Rpa43 in anaphase to remove PolI from the rDNA. Whether this clearance occurs via disruption of the Rpa43-Rrn3 interaction or via the dissolution of intra-PolI contacts will be determined in future research.

\section{Discussion}

We have identified Riol as a cell cycle-driven regulator of rDNA transcription, pre-rRNA processing, rDNA stability and segregation (Fig. 9). Yeast SSU processome mutants arrest at cell cycle entry (START) because pre-rRNA does not become processed and ribosomes are not being synthesized ${ }^{58}$. Our cell cycle experiments revealed that G1 cells lacking nuclear Rio1 activity accumulate primary $35 \mathrm{~S}$ transcripts but also prerRNA species not yet processed at $\mathrm{A}_{2}$ (RT-qPCR analysis with a probe covering the $\mathrm{A}_{2}$ site; Supplementary Fig. 9c). These anomalies may help to explain the delay at START of our mutant.

In $\mathrm{S}$ phase, Rio1 acts at multiple levels. By tuning down transcription by PolI, Riol may reduce the frequency of collisions between the replisome and PolI within the 35 S sequence, hence minimizing the production of double-strand breaks and incomplete transcripts ${ }^{59}$. Excessive PolI activity may also lead to extreme supercoiling and aberrant chromatin structures that stimulate DNA breakage and recombination. During rDNA replication, the RFB-bound proteins prevent the replisome from entering the $35 \mathrm{~S}$ rDNA sequence and promote a correct alignment of the newly replicated sister rDNA arrays. Their recruitment of Riol indicates an involvement of the kinase in regulating these RFB activities. Riol also localizes the histone deacetylase Sir2 to rDNA chromatin. Sir2 promotes rDNA

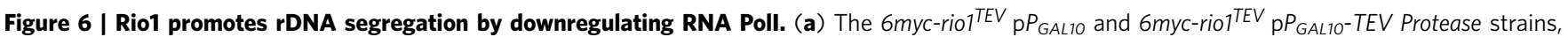
carrying the cdc14-3 allele and marked with a 256xtetO TetR-GFP array flanking RDN1 (rDNA-GFP) were arrested in G1 ( $2 \%$ raffinose medium, $23^{\circ} \mathrm{C}$ ). Cells were then released into the cell cycle $\left(2 \%\right.$ raffinose medium, $\left.37^{\circ} \mathrm{C}\right)$ and arrested in early anaphase by inactivation of $\mathrm{Cdc} 14-3.2 \%$ Galactose was then added to induce $P_{\text {GAL10 }}$ while the $\mathrm{Cdc} 14-3$ protein was re-activated in parallel (downshift to $23^{\circ} \mathrm{C}$ ). rDNA-GFP movement and segregation of the sister rDNA loci was tracked through anaphase by live-cell fluorescence microscopy. Left plots: single-cell rDNA segregation profiles. Projected movements of the sister rDNA arrays are shown in dark and light blue or in dark and light red colours. Right plots: percentage of cells with segregated sister rDNA-GFP loci, and the maximum length of their late-anaphase spindles. Error bars, s.d.'s. $n=$ Indicated. (b) Sketch of $35 \mathrm{~S}$ pre-RNA processing into $20 \mathrm{~S}$ and $27 \mathrm{SA} \mathrm{A}_{2}$ prerRNA. The graphs show the quantification of primary $35 \mathrm{~S}$ rRNA levels measured by RT-qPCR ( $5^{\prime} E T S$ probe 4$)$ or by northern blot analysis $\left(+1-A_{0}\right.$ probe) of $c D N A$ or total RNA, respectively. 6 myc-rio ${ }^{T E V}$ cdc15-2 cells carrying $\mathrm{PP}_{\text {GAL10 }}$ (blue) or $\mathrm{PP}_{\text {GAL10-TEV Protease (red) were released from a metaphase arrest }}$ (nocodazole) under $P_{G A L 10}$-inducing conditions $\left(37^{\circ} \mathrm{C}\right)$. Error bars, s.d.'s. $n=2$. The northern blot with the $+1-\mathrm{A}_{0}$ probe is shown underneath the graph. $(\mathbf{c})$ ChIP-qPCR based measurement of Rpa43 levels at the rDNA of cdc15-2 6myc-rio TEV PP $_{\text {GAL10 }}$ (blue) and cdc15-2 6myc-rio $1^{\text {TEV }}$ pP $P_{\text {GAL10 }}$-TEV Protease cells (red) arrested in anaphase following release from a metaphase arrest $\left(37^{\circ} \mathrm{C}, 2 \%\right.$ galactose medium). Rpa43 levels across the rDNA unit were measured with probes 2-5. (d) RT-qPCR based quantification of primary $35 \mathrm{~S}$ rRNA levels ( $5^{\prime}$ ETS probe 4 ) in 6 myc-rio ${ }^{\text {TEV }}$ cdc14-3 carrying p $P_{\text {GAL10 }}$ (blue) or pP $P_{\text {GAL10- }}$ TEV Protease (red) arrested in anaphase $\left(37^{\circ} \mathrm{C}\right.$ ) after release from a metaphase arrest (nocodazole) under $P_{G A L 10}$-inducing conditions. Reported values are normalized to the $35 \mathrm{~S}$ levels measured for $c d c 15-26$ myc-rio $^{T E V} p P_{G A L 10}$ cells, as indicated with a dashed line (Fig. $6 \mathrm{~b}$ ). Error bars, s.d.'s. $n=3$. 
a

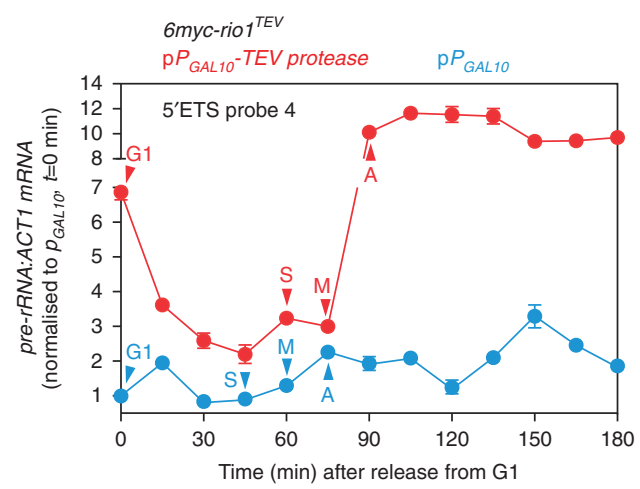

b
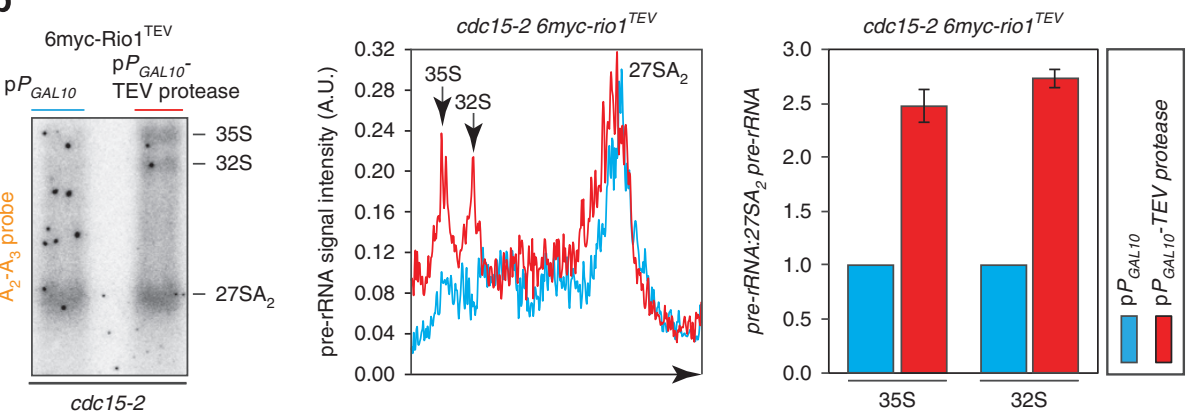

C
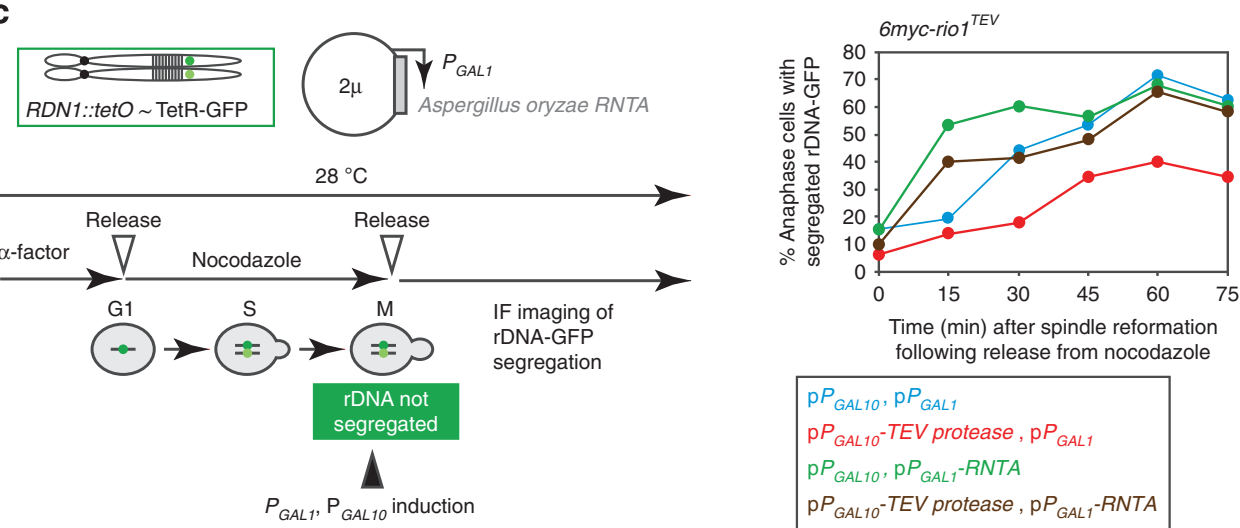

Figure 7 | Rio1 promotes rDNA segregation by removing RNA Poll and by stimulating the nucleolar processing of pre-rRNA transcripts. (a) RT- $q P C R$ analysis of $35 \mathrm{~S}$ cDNA (5'ETS probe 4) from 6myc-rio $7^{T E V} \mathrm{pP}_{\text {GAL1O }}$ (blue) and 6myc-rio $1^{T E V} \mathrm{pP}_{\text {GAL10 }}$-TEV Protease (red) cells synchronously released from G1 into the cell cycle ( $2 \%$ galactose medium). $P_{\text {GAL10 }}$ was induced $1 \mathrm{~h}$ before releasing the $\mathrm{G} 1$ arrested cells. Error bars, s.d.'s. $n=3$. (b) Left: northern blot analysis with an $\mathrm{A}_{2}-\mathrm{A}_{3}$ probe of total RNA isolated from 6 myc-rio $1^{T E V}$ cdc14-3 cells carrying $\mathrm{p} P_{\text {GAL10 }}$ (blue) or pP $P_{\text {GAL10 }}$-TEV Protease (red). The cells were arrested in anaphase after release from a metaphase arrest (nocodazole, $23^{\circ} \mathrm{C}$ ) under $P_{G A L 10}$-inducing conditions $\left(37^{\circ} \mathrm{C}\right.$ ). Right: quantified northern blot signals, and $35 \mathrm{~S}$ and $32 \mathrm{~S}$ pre-rRNA levels relative to those of $27 \mathrm{SA} \mathrm{A}_{2}$ pre-rRNA. (c) 6 myc-rio $7^{T E V} \mathrm{p} P_{\text {GAL10 }}$ and 6 myc-rio $^{T E V} \mathrm{pP} P_{\text {GAL10-TEV Protease cells marked }}$ with a 256xtetO $\sim$ TetR-GFP array at $R D N 1$, containing the $\mathrm{p} P_{G A L 1}-A$. oryzae RNTA or the $\mathrm{p} P_{G A L 1}$ control vector. The strains were arrested in metaphase (nocodazole) and released into anaphase under $P_{G A L T^{-}}$and $P_{G A L 10^{-}}$inducing conditions (2\% galactose medium). rDNA-GFP segregation was tracked through anaphase by live-cell fluorescence microscopy ( $n=30$ cells per time point).

stability by localizing both to the RFB and also to the cryptic E-Pro promoter. By repressing PolII-mediated transcription from E-Pro, Sir2 prevents the synthesis of non-coding E-Pro transcripts that displace the cohesin complexes and cause the sister arrays to misalign ${ }^{36}$. Double-strand rDNA breaks repaired by recombination between misaligned sister arrays results in rDNA repeat-number expansion or reduction, and in the formation of $\mathrm{ERCs}^{27,28}$. Both ERC accumulation and rDNA repeat-number instability have been linked to senescence (shortened lifespan) ${ }^{29,30}$, suggesting that Riol may determine yeast life expectancy. When rDNA repeat numbers fall below wild-type level, reduced repression of E-Pro may promote unequal recombination and increase repeat numbers. As such,
Riol could act as a monitor of rDNA copy number and as an array manager by dictating Sir2 levels and activity.

Once cells have endured rDNA replication, repression of PolI activity may no longer be necessary in metaphase. As such, Rio1 dissociating from the metaphase nucleolus may lead to a temporal increase in rDNA transcription before Poll becomes downregulated in anaphase. Rio1, together with the conserved Cdc14 phosphatase, reduce PolI activity by targeting Rpa43, a subunit of the Rpa14-Rpa43 dimer, that lies at the outer edge of PolI and mediates PolI recruitment by Rrn3 (refs 42,43). The concurrent action by Rio1 and Cdc14 may establish a local phosphothreshold that commands the dissociation of PolI from 35S at anaphase entry. 
a

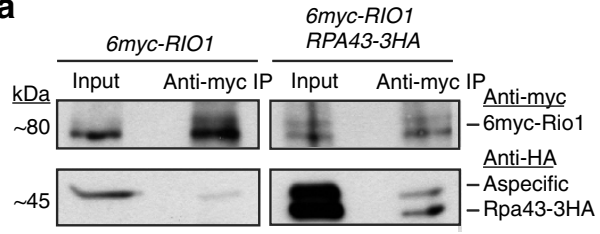

C

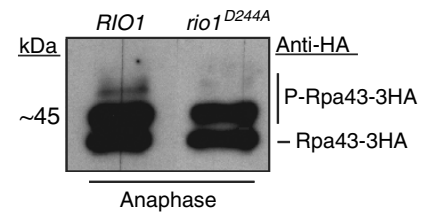

e

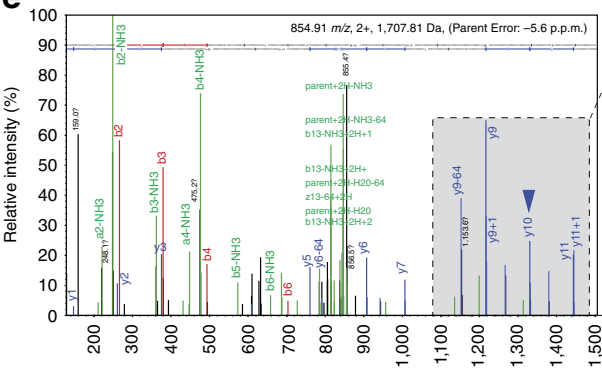

b

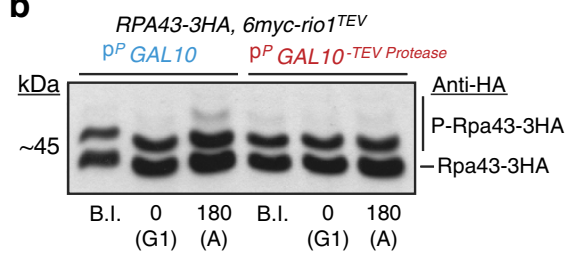

d

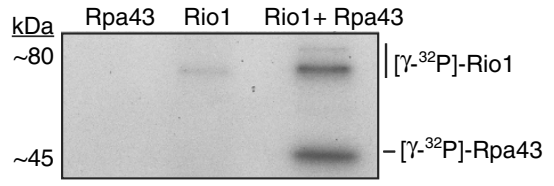

$m / z$

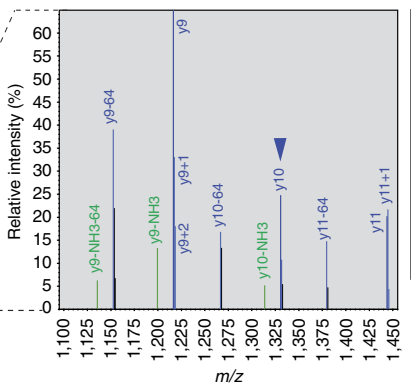

(K)QHLNPLVmkyNNK(V) Oxidation $(+15.995 \mathrm{Da})$ Methyl (+14.016 Da) Phospho (+79.966 Da) Scan 5225 Sequest Xcorr 2.1 Mascot Ion Score 30.9 MS Amanda Score 270.1

f 10
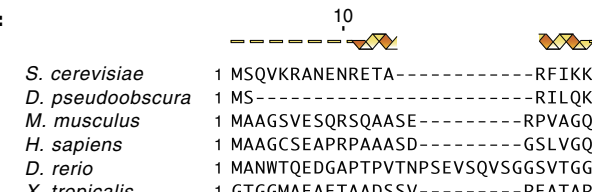

$20 \quad 30$

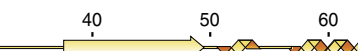

1 MSQVKRANENRETA----_-----RFIKKHKKQVTNPIDEK-------NGTSNCIVRVPIALYVSLAPMYLENPLQGVMKQH 65

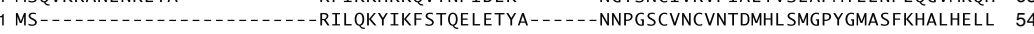
1 MAAGSVESQRSQAASE---RPVAGQAGVLPCLELPSYAAACALVGSRYSCLVAAPHRRHIALSPRYLSRKRTGIREQ- 74 1 MAAGCSEAPRPAAASD-------GSLVGQAGVLPCLELPTYAAACALVNSRYSCLVAGPHQRHIALSPRYLNRKRTGIREQ- 74 1 MANWTQEDGAPTPVTNPSEVSQVSGGSVTGGPAVTSCL-IPSFAEAVKLLKARYSCLVLDTHRRHISLPPVHLKKKKTGIQEQ- 82 1 GTGMAEAETAADSSV----PEATAPARALPSLALPSFSEACELVRSRYSCLVVETHRRHLTLSPKFLQKKRSGLQEQ -74

$\stackrel{70}{1} \longrightarrow$

S. cerevisiae 66 LNPLVMKYNNNKVGGVVLGYEGLKILDADPLSKEDTSEKLIKITPDTPFGFTWCHVNLYVWOPOVGDVLEGYIFIOSASHIGLLI 149

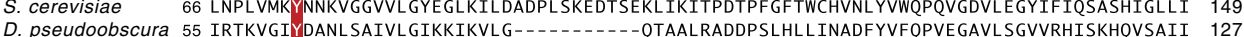
$\begin{array}{llll}\text { D. } p s e u d o o b s c u r a & 55 & \text { IRTKVGIYDANLSAIVLGIKKIKVLG--------QTAALRADDPSLHLLINADFYVFQPVEGAVLSGVVRHISKHQVSAII } & 127 \\ \text { M. musculus } & 75 \text { LDAELLRYSESLLGVPIAYDNIRVVG-------ELGDIYDDOGHIHLNIEADFVIFCPEPGOTLMGTVNKVSSSHIGCLV } & 147\end{array}$ $\begin{array}{ll}\text { M. musculus } & 75 \text { LDAELLRYSESLLGVPIAYDNIRVVG-------ELGDIYDDQGHIHLNIEADFVIFCPEPGQTLMGTVNKVSSSHIGCLV } 147 \\ \text { H. sapiens } & 75 \text { LDAELLRYSESLLGVPIAYDNIKVVG------ELGDIYDDQGHIHLNIEADFVIFCPEPGQKLMGIVNKVSSSHIGCLV } 147\end{array}$

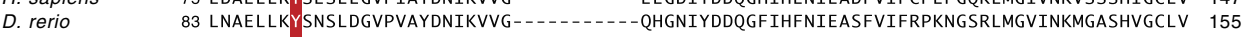
$X$. tropicalis 75 LNTDLLKYNEGLKGVPVAYDSIKLVG-_...-_---ELGDIFDDLGHIHINIEADFVIFNPKCGQTLVGIVNKVAPTHIGCLV 147
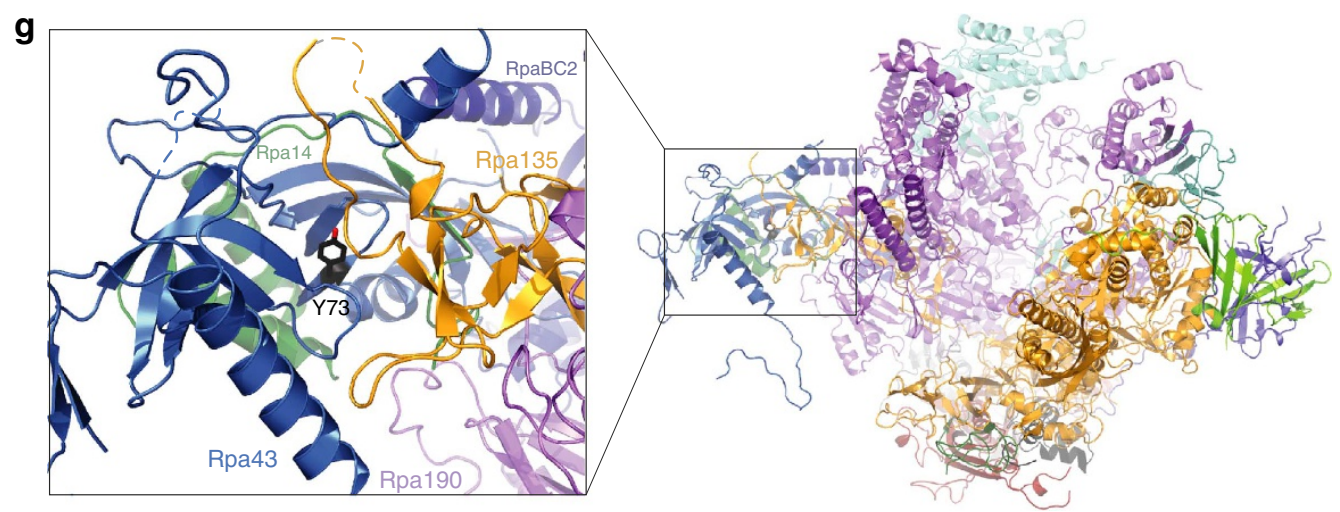

Figure 8 | Rio1 downregulates RNA Poll by targeting subunit Rpa43. (a) 6myc-Rio1 and Rpa43-3HA co-immunoprecipitate from whole-cell extract derived from exponentially growing 6myc-RIO1 RPA43-3HA cells. (b) PhosTag western blot of Rpa43-3HA (anti-HA) in 6myc-rio1 TEV $\mathrm{pP}$ GAL10 (blue) and 6 myc-rio1 ${ }^{T E V} \mathrm{pP}_{\text {GAL10 }}$-TEV Protease (red) cells. Cells were collected before $P_{\text {GAL10 }}$ induction (B.I.), after $1 \mathrm{~h}$ of induction during the $\mathrm{G} 1$ arrest (G1), and $3 \mathrm{~h}$ after the release from G1 (anaphase, A). (c) PhosTag western blot of Rpa43-3HA (anti-HA) in RPA43-3HA cells inducibly expressing wild-type RIO1 or the dominant-negative kinase-dead rio ${ }^{D 244 A}$ allele from $P_{G A L 1}$ on a $2 \mu$ plasmid. The cells were collected in anaphase $3 \mathrm{~h}$ after release from $\mathrm{G} 1$ in $2 \%$ galactose medium. (d) In vitro kinase assay with recombinant His6-Rio1 $(1 \mu \mathrm{g})$ and recombinant Rpa43-His6-HA (6 $\mu \mathrm{g})$ in the presence of $0.05 \mu \mathrm{M}[\gamma-32 \mathrm{P}] \mathrm{ATP}$. The radiographs show phosphorylated His6-Rio1 and Rpa43-His6-HA. (e) NanoLC-MS/MS spectrum of the Rpa43 QHLNPVMKY73NNK phospho-peptide. The position of phospho-Y73 is indicated with an arrowhead. (f) Alignment of the Rpa43 proteins from Saccharomyces cerevisiae, Drosophila pseudoobscura, Mus musculus, Homo sapiens, Dario rerio and Xenopus tropicalis (UniProtKB database entries: A6ZPH0, Q29JY4, Q78WZ7, Q3B726, Q6PHG8 and F7BDD1, respectively) using Muscle (www.ebi.ac.uk/Tools/msa/muscle). The S. cerevisiae Y73 residue and its equivalents in the Rpa43 orthologues are indicated in white font on a red background. (g) Localization of Rpa43 Y73, indicated in black, within the 14-subunit RNA Poll enzyme complex ${ }^{57}$ (top view rotated $+90^{\circ} ;$ PDB 4(3J). 


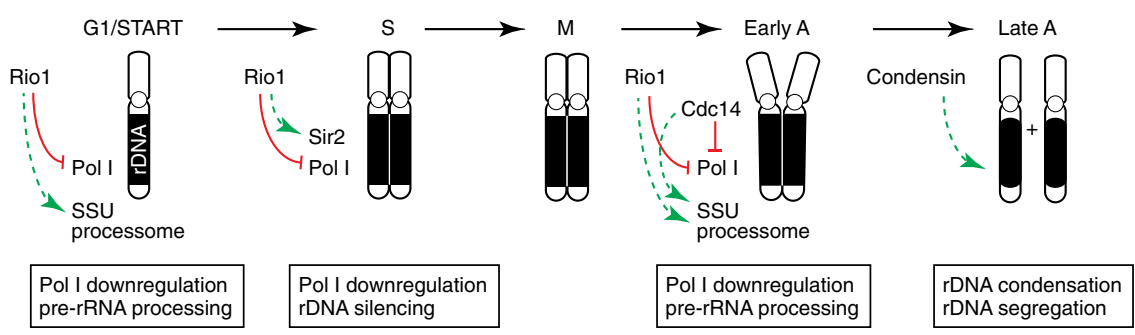

Figure 9 | Rio1 downregulates RNA Poll to promote rDNA stability and segregation. Working model of Rio1-mediated regulation of rDNA transcription, pre-rRNA processing, rDNA stability and segregation, as identified in this study. In G1, Rio1 downregulates $35 \mathrm{~S}$ rDNA transcription by Poll and promotes pre-rRNA processing at $A_{2}$ by the SSU processome and associated factors, allowing for a timely commencement of the cell cycle at START. In S phase, the Rio1-mediated downregulation of Poll and recruitment of the histone deacetylase Sir2 to rDNA chromatin, promote rDNA stability. As rDNA replication progresses, Rio1 concentrations at S phase rDNA decrease, resulting in metaphase nuclei containing low levels of Rio1. At anaphase onset, Rio1 becomes rerecruited to the nucleolus to remove Poll from the rDNA by targeting Poll subunit Rpa43. Poll delocalization and promotion of pre-rRNA processing at the rDNA allow for condensin enrichment, resulting in rDNA compaction and segregation. Red lines: inhibitory activity, green lines: activating activity, solid lines: direct activity, dashed lines: direct or indirect activity.

By downregulating PolI and by stimulating PolI transcript processing at the $\mathrm{A}_{2}$ site (as mediated by the SSU processome), Riol promotes condensin binding and rDNA transmission. Indeed, without Riol activity, the long right arm of chromosome XII harbouring the rDNA array does not segregate into the daughter cells, resulting in chromosome loss. We also observed that condensin itself recruits Riol to anaphase rDNA, suggesting that Rio1 might also promote condensin activity. The monopolin complex, which tethers the nucleolus to the nuclear membrane via the CLIP (Chromosome Linkage Inner nuclear membrane Protein) complex ${ }^{48}$, also recruits Riol to anaphase rDNA. It is tempting to speculate that Riol targeting monopolin may facilitate rDNA segregation by inducing rDNA detachment from the nuclear envelope.

Rio1 and its human orthologue RIOK1 promote the endonucleolytic cleavage of $20 \mathrm{~S}$ pre-rRNA at pre-40S ribosomes, and stimulate the recycling of trans-acting factors that catalyse $40 \mathrm{~S}$ maturation ${ }^{12,18-20}$. While these events occur in the cytoplasm, a small pool of RIOK1 also localizes to the human nucleus ${ }^{19,20}$. Treating murine cells with toyocamycin, an inhibitor of Rio1 activity in $v i t r 0^{61}$, impeded nucleolar pre-rRNA processing ${ }^{62}$, indicating that RIOK1 might be involved in early pre-rRNA cleavage, as we observed for Riol in yeast.

In contrast to yeast, vertebrate cells contain five rDNA clusters on different chromosomes. In prophase, these nucleoli disassemble and their transcription becomes repressed to allow the stripped rDNA to segregate with the rest of the genome. Nucleolar transcription is downregulated by the CDK1-cyclin B kinase, whose phosphorylation of promoter selectivity factor SL1 prevents the formation of the PolI pre-initiation complex ${ }^{63-65}$. Similar to yeast Rio1, RIOK1 might just as well contribute to the transcriptional repression of PolI.

In conclusion, our study reveals the first nuclear functions of the Rio1 kinase. By downregulating PolI-mediated rDNA transcription and by promoting the processing of its transcripts, Riol ensures both a timely commencement and conclusion of the cell cycle (rDNA segregation permits exit from mitosis). Rio1 safeguards rDNA stability during DNA replication and integrates early nucleolar and late cytoplasmic events during ribosome biogenesis. As such, Rio1 activity allows yeast to actively grow and divide while ensuring the integrity and faithful transmission of its genome.

\section{Methods}

Yeast strains. Yeast strains (W303-1A background; Supplementary Table 1) were made by mating, tetrad dissection and spore selection, by introducing integrative or episomal plasmids or via transformation and homologous recombination of PCRgenerated deletion or epitope cassettes. None of the epitopes affected yeast fitness or the activity of the tagged protein. The plasmids used in this study are listed in Supplementary Table 2 .

To generate the $6 m y c$-rio $1^{T E V}$ strain, 21 nucleotides (5'-GAAAACCTGTATT TTCAGGGC- $3^{\prime}$ ) encoding the TEV Protease cleavage site (ENLYFQG) were introduced by PCR between the nucleotides encoding Rio1 residues E406 and E407 in an integrative URA3-based plasmid harbouring $6 m y c-R I O 1$ under control of its endogenous promoter, $P_{R I O 1}$. After linearization in $P_{R I O I}$ by the endonuclease SgraI, the plasmid was integrated at the endogenous $P_{R I O 1}$ in the genome of parent strain PDW001. Following incubation on complete minimal medium containing $1 \mathrm{gl}^{-1} 5$ fluoroorotic acid (Fluka), we PCR-identified the colonies in which wild-type RIO1 had been recombined out, leaving the $6 m y c$-riol allele expressed from $P_{R I O I}$ and harbouring the TEV Protease cleavage site (named $6 m y c-r i o 1^{T E V}$ ) as the only source of Riol. The episomal high-copy $2 \mu \mathrm{p} P_{G A L 10}-H A-T E V$ Protease-NLS plasmid was made by subcloning the HA-TEV Protease-NLS sequence from pYeF1-TEV (ref. 66) into the HIS3-marked $P_{\text {GAL10 }}$ expression plasmid pYeHFc2H ( $P_{\text {GAL10 }}$, gift from C. Cullin) as well as into $\mathrm{pYeHFc2H}$ provided with geneticin-resistance cassette $K a n M X 4$. After transforming the $6 m y c-$ riol ${ }^{T E V}$ strain, we obtained strain $6 m y c$ rio1 ${ }^{T E V} \mathrm{p} P_{G A L 10}-T E V$ Protease and the 6 myc-rio1 $^{T E V} \mathrm{p} P_{\text {GAL10 }}$ control strains.

Cell cycle studies. Cells were grown at $23^{\circ} \mathrm{C}$ in minimal synthetic drop-out media or in YEPA medium ( $1 \%$ yeast extract, $2 \%$ peptone and $0.3 \mathrm{mM}$ adenine) containing $2 \%$ raffinose, $2 \%$ galactose or $2 \%$ glucose. To arrest yeast in G1, S phase or metaphase, cultures were treated $(2.5-3 \mathrm{~h})$ with $5 \mu \mathrm{g} \mathrm{ml}^{-1} \alpha$-factor (GeneScript), $10 \mu \mathrm{g} \mathrm{ml}^{-1}$ hydroxyurea (Sigma-Aldrich) or $15 \mu \mathrm{g} \mathrm{ml}^{-1}$ nocodazole (SigmaAldrich), respectively. To release the cells into the cell cycle, we filtered the yeast cultures, washed and then resuspended the cells in drug-free medium. To arrest the cells in anaphase, strains carrying either the temperature-sensitive $c d c 15-2$ or cdc14-3 allele were first arrested in G1 or metaphase $\left(23^{\circ} \mathrm{C}\right)$ and then released at the non-permissive temperature $\left(37^{\circ} \mathrm{C}\right)$.

To deplete Riol activity from the nucleus, both the $6 m y c-r i o 1^{T E V} \mathrm{p} P_{G A L 10}-T E V$ Protease strain and the 6 myc-riol ${ }^{T E V} \mathrm{p} P_{\text {GAL10 }}$ negative-control strain were grown in $2 \%$ raffinose YEPA medium (raffinose does not affect $P_{G A L 10}$ ) containing $220 \mu \mathrm{g} \mathrm{ml}^{-1}$ geneticin (G418, Life Technologies). While arrested or during exponential growth, the cells were treated with $2 \%$ galactose to induce $P_{\text {GAL1O }}$ (for $1 \mathrm{~h}$ during the arrest, for $3 \mathrm{~h}$ during exponential growth). Arrested cells were then released in medium containing $2 \%$ galactose, $2 \%$ raffinose and $220 \mu \mathrm{g} \mathrm{ml}^{-1} \mathrm{G} 418$.

For rDNA and ERC analysis, total DNA was extracted from cells grown for $15 \mathrm{~h}$ (eight divisions) in $2 \%$ galactose medium, run on a $0.6 \%$ TBE-agarose gel, transferred for Southern blot analysis and hybridized with a $25 \mathrm{~S}$ rDNA probe ${ }^{32}$. The oligomers used to produce the probe are listed in Supplementary Table 3.

Progression through the cell cycle was tracked by indirect IF microscopy analysis of spindle morphology (see further down) and by FACS analysis of DNA content. Regarding the latter, cells were fixed in $70 \%$ ethanol, incubated first with $1 \mathrm{mg} \mathrm{ml}^{-1}$ RNAse A (Sigma-Aldrich), then with $5 \mathrm{mg} \mathrm{ml}^{-1}$ pepsin (SigmaAldrich) and ultimately resuspended in $1 \mathrm{mg} \mathrm{ml}^{-1}$ propidium iodide (Sigma-Aldrich). After mild sonication, cell fluorescence was analysed with a FACScan (Becton Dickinson) sorter and DNA content profiles generated with CellQuest software.

IF imaging of yeast cells was performed with $1 \mathrm{ml}$ of cell culture. The cells were centrifuged and crosslinked overnight in $1 \mathrm{ml}$ of $3.7 \%$ formaldehyde. The cell walls were then digested $(30 \mathrm{~min})$ with zymolyase $\left(100 \mu \mathrm{g} \mathrm{ml}^{-1}\right.$, Amsbio), washed with $1.2 \mathrm{M}$ sorbitol and $100 \mathrm{mM}$ phospho-citrate, $\mathrm{pH} 5.9$, and bound to a multiwall poly-L-lysine-coated glass slide (Sigma-Aldrich). The slide was treated with DAPI and hybridized with rat monoclonal anti-Tub1 (YOL1/34, Adb Serotec MCA78G), rabbit polyclonal anti-GFP (Life Technologies,A-6455), goat polyclonal anti-Cdc14 (yE-17, Santa Cruz Biotech sc-12045) or mouse monoclonal anti-myc (9E10, Covance MMS-150R) primary antibodies. CY3 (715-165-151)- or fluorescein isothiocyanate (FITC; 111-095-144)-labelled secondary antibodies (Jackson Laboratory) were used to visualize the proteins. 
IF imaging of rDNA or centromeres in fixed cell samples was done as described above and performed with strains whose RDN1 or CEN4 sequence was flanked with a $256 x$ tet $O \sim$ TetR-GFP array. Images were acquired with a DeltaVision ELITE microscope (Applied Precision) carrying an Olympus IX71 UPlanSApo objective lens (numerical aperture 1.40) and a CoolSnap HQ2 CCD Camera (Photometrics). Fifteen Z-stacks were acquired every $0.4 \mu \mathrm{m}$, deconvoluted (SoftWoRx) and projected with maximum intensity.

IF imaging of spread nuclei was performed using $4 \mathrm{ml}$ of cell culture. The cells were centrifuged and digested with zymolyase $\left(30 \mu \mathrm{g} \mathrm{ml}^{-1}\right)$. The spheroblasts were then fixated on a glass slide with $4 \%$ paraformaldehyde and $3.4 \%$ sucrose, and spread with a glass rod. The slides were then hybridized with rabbit polyclonal antiGFP (Life Technologies A-6455), mouse monoclonal anti-HA (16B12, Covance MMS-101P), mouse monoclonal anti-myc (9E10, Covance MMS-150R), mouse monoclonal anti-Nop1 (28F2, EnCore Biotech MCA28F2), rabbit polyclonal antiRiol (gift from J.-P. Gelugne) or goat polyclonal anti-Sir2 (yN-19, Santa Cruz Biotech sc-6666) antibodies. CY3- or FITC-labelled secondary antibodies (Jackson Laboratory, see above) were used. Nuclei were imaged with a BX51 wide-field fluorescence microscope (Olympus).

Live-cell imaging of spindle (mCherry-Tub1) elongation and RDN1-GFP segregation was performed with microfluidic plates (CellASIC) and a DeltaVision microscope setup as described above via $15 \mathrm{Z}$-stacks $(0.4 \mu \mathrm{m}$ each). The images were deconvoluted (SoftWoRx), projected with maximum intensity and analysed with ImageJ1.43u (National Institutes of Health, N.I.H.).

Immunobloting. Cells were collected, treated with 5\% trichloroacetic acid (TCA), resuspended in lysis buffer (50 mM Tris-Cl pH7.5, $1 \mathrm{mM}$ EDTA.Na $\mathrm{N}_{2}, 50 \mathrm{mM}$ dithiothreitol, $60 \mathrm{mM} \beta$-glycerophosphate, $0.1 \mathrm{mM} \mathrm{Na}_{3} \mathrm{VO}_{4}$ and $5 \mathrm{mM} \mathrm{NaF}$ ) containing protease inhibitors (Roche) and then disrupted with glass beads and a FastPrep-24 instrument (MP Biomedicals). Lysates were cleared by centrifugation, resuspended in sample loading buffer (8\% SDS, $200 \mathrm{mM}$ Tris-Cl, $\mathrm{pH} 6.8,400 \mathrm{mM}$ dithiothreitol, $0.4 \%$ bromophenol blue and $40 \%$ glycerol), heat-denatured and run on SDS polyacrylamide gels. To separate the phospho species of Rpa43-3HA, the SDS polyacrylamide gels were provided with $30 \mu \mathrm{M}$ PhosTag (Manac Incorporated). Proteins were transferred onto Immobilon-P membranes (Millipore) and incubated with mouse monoclonal anti-Pgk1 antibody (1:5,000; Life Technologies 459250), mouse monoclonal anti-Rad53 EL7E1 $\left(4 \mu \mathrm{g} \mathrm{ml}^{-1}\right.$, gift from M. Foiani), goat polyclonal anti-Cdc14 yE-17 (1:1,000; Santa Cruz sc-12045), mouse monoclonal anti-Flag M2 (1:4,000; Sigma-Aldrich A2220), mouse monoclonal anti-Myc 9E10 (1:1,000; Covance MMS-150R), mouse monoclonal anti-HA 16B12 (1:1,000; Covance MMS-101P) or mouse monoclonal anti-HIS H-3 (1:200, Santa Cruz sc-8036) antibodies. Horseradish peroxidase (HRP)-conjugated goat antimouse (1:10,000; Bio-Rad 170-6516) or goat anti-rabbit (1:10,000; Bio-Rad 170$6515)$ secondary antibodies were used to visualize the proteins with ECL chemiluminescence (GE Healthcare) and radiography film (GE Healthcare). Uncropped blots are shown in Supplementary Fig. 11.

To probe the interaction between 6myc-Riol and Rpa43-3HA or between 6 myc-Riol and Sgs1-3FLAG, yeast whole-cell extract ( $3 \mu \mathrm{g}$ of total protein) was incubated with anti-myc sepharose matrix (9E10, Covance AFC-150P) or anti-HA sepharose matrix (3F10, Roche 11815016001). Following four washes with high salt and detergent buffer (50 mM HEPES, pH 7.5, $500 \mathrm{mM} \mathrm{NaCl}, 2.5 \mathrm{mM} \mathrm{MgCl}_{2}, 0.5 \%$ Nonidet P (NP)-40 and 10\% glycerol), Rpa43-3HA, 6myc-Riol or Sgs1-3Flag were visualized by western hybridization analysis.

Rio1 kinase activity measurements. To measure the kinase activity of full-length or truncated $6 \mathrm{myc}^{-R_{i o} 1^{\mathrm{TEV}}}$, cells were grown in $2 \%$ raffinose medium, arrested in G1 and collected before, upon and after $P_{\text {GALIO }}$ induction with $2 \%$ galactose. Cells were resuspended in lysis buffer (50 mM HEPES-KOH, pH 7.1, 50\% glycerol, $300 \mathrm{mM} \mathrm{NaCl}, 1 \% \mathrm{NP}-40,1 \mathrm{mM}$ Na3VO4, $1 \mathrm{mM} \mathrm{NaF}$ and $1 \mathrm{mM}$ phenylmethylsulfonyl fluoride (PMSF)) and whole-cell extracts made with glass beads. Cleared extract (500 $\mu \mathrm{g}$ of protein) was then incubated $\left(4^{\circ} \mathrm{C}\right.$, overnight) with anti-myc sepharose beads (Covance). The beads were washed once with washing buffer (50 mM HEPES-KOH, pH 7.1, $300 \mathrm{mM} \mathrm{NaCl}, 1 \% \mathrm{NP}-40,1 \mathrm{mM} \mathrm{Na}_{3} \mathrm{VO}_{4}, 1 \mathrm{mM}$ $\mathrm{NaF}$ and $1 \mathrm{mM}$ PMSF), and three times with kinase buffer (50 mM HEPES-KOH,

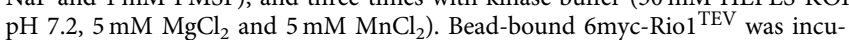
bated with $1.5 \mathrm{mg} \mathrm{ml}^{-1}$ of dephosphorylated casein (Sigma-Aldrich) and $0.03 \mu \mathrm{M}$ $[\gamma-32 \mathrm{P}]$ ATP $\left(\right.$ PerkinElmer) in kinase buffer. The assay $\left(15 \mathrm{~min}, 24^{\circ} \mathrm{C}\right)$ was performed in the presence or absence of CK1 and CK2 kinase inhibitors $(5 \mu \mathrm{M}$ each; CKI-7 dichlorhydrate and 4,5,6,7-tetrabromobenzotriazole (TBB), respectively; Sigma-Aldrich). The reactions were analysed on SDS polyacrylamide gels, which were then fixed in a $30 \%$ methanol $+10 \%$ acetic acid solution, and dried on a Gel Dryer (Bio-Rad). The phospholabelled proteins were visualized by autoradiography and quantified using ImageJ.

RT-qPCR analysis of rRNA. Total RNA was isolated ${ }^{67}$ from cells collected through the cell cycle or enriched at a specific cell cycle stage. RNA $(1 \mu \mathrm{g})$ was retrotranscribed into cDNA with Random Primers (Life Technologies) and ImProm-II Reverse Transcriptase (Promega). cDNA ( $5 \mathrm{ng}$ ) was analysed by RT-qPCR analysis (7500 Fast Real-Time PCR, Life Technologies) using TaqMan probes (Life Technologies; Supplementary Table 3) against the $5^{\prime}$ ETS sequence of
$35 \mathrm{~S}$ pre-rRNA (probe 4 in the figures) or against the $\mathrm{A}_{2}$-processing site of $35 \mathrm{~S}, 33 \mathrm{~S}$ and $32 \mathrm{~S}$ pre-rRNA (probe 6). ACT1 cDNA (housekeeping control) was used as the internal reference. Analyses were done in triplicate.

ChIP-qPCR analysis. For each analysis, $50 \mathrm{ml}$ of cell culture were treated with $1 \%$ formaldehyde $(2 \mathrm{~h})$. Crosslinked cells were washed with Tris-buffered saline $(50 \mathrm{mM}$ Tris-Cl, $\mathrm{pH} 7.5,150 \mathrm{mM} \mathrm{NaCl})$ and resuspended in lysis buffer $(50 \mathrm{mM}$ HEPES, pH 7.5, $140 \mathrm{mM} \mathrm{NaCl}, 1 \mathrm{mM}$ EDTA, $1 \%$ Triton X-100 and $0.1 \%$ sodium deoxycholate). The cells were broken with glass beads and the whole-cell extracts were sonicated on ice with a Branson Sonifier $250(5 \times 30$ s, 2 min on ice $)$ to reduce the genome in $\sim 500 \mathrm{bp}$ fragments. Anti-myc sepharose beads and rabbit polyclonal anti-Rpa43 antibody (gift from M. Riva) conjugated to protein A-associated agarose beads (Pierce) were incubated $\left(4^{\circ} \mathrm{C}\right.$, overnight) with the extracts to isolate 6myc-Riol and Rpa43. The beads were then washed twice with lysis buffer, once with washing buffer (100 mM Tris-Cl, pH 8.0, 1 mM EDTA 1\% Triton X-100, $0.1 \%$ sodium deoxycholate, $0.5 \% \mathrm{NP}-40$ and $250 \mathrm{mM} \mathrm{LiCl}$ ) and once with TE buffer. The beads were resuspended $\left(10 \mathrm{~min}, 65^{\circ} \mathrm{C}\right)$ in elution buffer $(1 \%$ SDS, $50 \mathrm{mM} \mathrm{Tris}-\mathrm{Cl}$, $\mathrm{pH}$ 8.0, $10 \mathrm{mM}$ EDTA) and the eluted material then separated from the beads and heated $\left(65^{\circ} \mathrm{C}\right.$, overnight) to reverse the crosslinks. An amount of $25 \mu \mathrm{l}$ of total chromatin solution were similarly heat treated $(=$ Input). After treatment with $20 \mathrm{mg} \mathrm{ml}^{-1}$ proteinase $\mathrm{K}$ (Roche), the material was treated with $10 \mathrm{mg} \mathrm{ml}^{-1}$ RNase (Sigma-Aldrich) for $30 \mathrm{~min}$ at $37^{\circ} \mathrm{C}$, and the DNA was extracted with phenol and chloroform. Following precipitation, the DNA was resuspended in $40 \mu \mathrm{l}$ water. Input and immunoprecipitated samples were analysed by RT-qPCR (probes are indicated in the Figures 1a, $6 \mathrm{~b}$ and $6 \mathrm{c}$ and in Supplementary Table 3).

Yeast two-hybrid interaction screens. Yeast two-hybrid screens were performed by Hybrigenics Services (www.hybrigenics-services.com). The RIO1 coding sequence (YOR119C) was cloned as a C-terminal fusion to LEXA or the GAL4 encoding DNA-binding domain, or as an N-terminal fusion to LEXA or GAL4. The constructs were screened by mating and covered the complexity of the S. cerevisiae genomic library 5- to 14-fold. Prey fragments of positive clones were amplified by PCR, sequenced and the interacting sequences were identified in the GenBank database (NCBI).

Ribosome, protein translation and northern blot analysis. For ribosome profiling, $6 m y c-$ rio1 ${ }^{T E V} \mathrm{p} P_{G A L 10}$ and $6 m y c-$ riol ${ }^{T E V} \mathrm{pP}_{\text {GAL10 }}$-TEV Protease cells were grown exponentially in $2 \%$ raffinose medium to an $\mathrm{OD}_{600}=0.5$. Galactose $(2 \%)$ was added and samples were taken at the indicated time points and treated on ice (5 min) with $100 \mu \mathrm{g} \mathrm{ml}^{-1}$ cycloheximide to stabilize the polysomes. The cells were washed with extraction buffer $\left(20 \mathrm{mM}\right.$ Tris-Cl, $\mathrm{pH} 7.5,50 \mathrm{mM} \mathrm{KCl}, 10 \mathrm{mM} \mathrm{MgCl}_{2}$ and $100 \mu \mathrm{g} \mathrm{ml}^{-1}$ cycloheximide). The cells were broken with glass beads and the cleared extract $\left(\mathrm{OD}_{254}=5.0\right)$ was loaded on a $10.5 \mathrm{ml} 5-45 \%$ sucrose gradient in extraction buffer lacking cycloheximide. Following centrifugation ( $16 \mathrm{~h}$;

21,000 r.p.m.; SW41 Beckman rotor), gradients were collected at a $1 \mathrm{ml} \mathrm{min}^{-1}$ flow rate and the ultraviolet profile recorded at $254 \mathrm{~nm}$ by a ultraviolet detector (linked to BioLogic LB fractionator), visualized with LP Data View software (Bio-Rad) and exported to Excel (Microsoft Office).

For global translation analysis, cells were grown as described above. The cells were collected at an $\mathrm{OD}_{600}=0.5$ and washed with complete synthetic medium lacking methionine but containing $2 \%$ raffinose or $2 \%$ galactose. The cells were then resuspended in $1 \mathrm{ml}$ of the corresponding medium and pulse-labelled with $100 \mu \mathrm{Ci}$ of $5^{\prime}, 6^{\prime}\left[{ }^{3} \mathrm{H}\right]-\mathrm{L}$-methionine for $20 \mathrm{~min}$ at $23^{\circ} \mathrm{C}$. Total proteins (TCA insoluble fraction) were extracted and washed twice with cold acetone before resolubilization. The amount of newly synthesized proteins was quantified using a scintillation counter. The solubilized proteins were also separated on a Nu-PAGE 4-10\% gradient gel and Coomassie stained to evidence equal loading.

For northern hybridization analysis, total RNA was isolated from the whole-cell extracts submitted to ribosome profiling (see above). Denaturing agarose gel electrophoresis, transferring of the RNA onto a positive membrane and northern hybridization with ${ }^{32} \mathrm{P}$-labelled oligomers (Supplementary Table 3) were performed as described ${ }^{12}$.

In vitro phosphorylation of Rpa43 by Rio1. Recombinant Rpa43-His6-HA was produced in E. coli Rosetta BL21(DE3) cells. Expression of Rpa43-His6-HA from plasmid pRSET-43A (gift from M. Riva) was induced at an $\mathrm{OD}_{600}=0.5$ with $150 \mathrm{mM}$ IPTG $\left(3.5 \mathrm{~h}, 24^{\circ} \mathrm{C}\right)$. Cells were collected in lysis buffer $(20 \mathrm{mM}$ Tris-Cl, pH8.0, $300 \mathrm{mM} \mathrm{NaCl}, 10 \%$ glycerol, $20 \mathrm{mM}$ imidazole, $1 \mathrm{mM}$ PMSF and $1 \mathrm{mM}$ $\mathrm{Na}_{3} \mathrm{VO}_{4}$ ) and lysed with a French press (15,000 p.s.i.; Microfluidics). The extract was incubated with $\mathrm{Ni}^{2+}$-NTA beads (Qiagen). The beads were washed with $30 \mathrm{mM}$ imidazole and Rpa43-His6-HA eluted with $200 \mathrm{mM}$ imidazole before being submitted to size-exclusion chromatography (Superdex $200 \mathrm{HR}$ 10/30, GE Healthcare). Recombinant His6-Rio1 was produced in E. coli BL21-RIL cells and expressed from plasmid pQE32-HIS6-RIO1 (gift from M. Angermayr) ${ }^{21}$. Expression was induced $\left(3.5 \mathrm{~h} 30^{\circ} \mathrm{C}\right)$ at an $\mathrm{OD}_{600}=0.7$ with $1 \mathrm{mM}$ IPTG and the cells were collected in lysis buffer $\left(50 \mathrm{mM} \mathrm{NaH}_{2} \mathrm{PO}_{4}\right.$ pH8.0, $50 \%$ glycerol, $300 \mathrm{mM}$ $\mathrm{NaCl}, 1 \mathrm{mM} \mathrm{NaF}, 1 \mathrm{mM}$ PMSF, $1 \mathrm{mM} \mathrm{Na}_{3} \mathrm{VO}_{4}, 1 \mu \mathrm{g} \mathrm{ml}^{-1}$ apoprotein and leupeptine, $1 \mathrm{mg} \mathrm{ml}^{-1}$ lysozyme, $5 \mu \mathrm{g} \mathrm{ml}^{-1}$ DNase and $100 \mu \mathrm{g} \mathrm{ml}^{-1}$ RNAse). The cell extract, obtained with a French press, was incubated with $\mathrm{Ni}^{2}{ }^{2}$-NTA beads 
(Qiagen), which were then washed with $20 \mathrm{mM}$ imidazole. His6-Riol was eluted with $200 \mathrm{mM}$ imidazole and the buffer was then exchanged into $50 \mathrm{mM}$ HEPES, $\mathrm{pH} 7.5,5 \%$ glycerol, $1 \mathrm{\mu g} \mathrm{ml}^{-1}$ apoprotein and leupeptine using PD-10 columns (GE Healthcare). The purity of Rpa43-His6-HA and His6-Riol was confirmed via SDS-PAGE and GelCode Blue (Pierce) staining.

To examine phosphorylation of Rpa43-His6-HA by His6-Rio1, $1 \mu \mathrm{g}$ of His6Rio1, $6 \mu \mathrm{g}$ of Rpa43-His6-HA and $0.05 \mu \mathrm{M}(5 \mu \mathrm{Ci})\left[\gamma_{-}{ }^{32} \mathrm{P}\right] \mathrm{ATP}$ (PerkinElmer) were incubated $\left(2 \mathrm{~h}, 30^{\circ} \mathrm{C}\right)$ in reaction buffer $(50 \mathrm{mM}$ HEPES-KOH, pH 7.2, $5 \mathrm{mM}$ $\mathrm{MgCl}_{2}$ and $5 \mathrm{mM} \mathrm{MnCl} 2$ ). Phosphorylated Rpa43-His6-HA was visualized radiographically. In the control reactions, only His6-Riol or Rpa43-His6-HA was present. To produce phosphorylated Rpa43-His6-HA for mass spectrometric analysis, five kinase reactions were set up, pooled (giving $30 \mu \mathrm{g}$ Rpa43-His6-HA) and separated by SDS-PAGE. Proteins were stained with GelCode Blue, Rpa43-His6-HA then excised from the gel, submitted to proteolytic cleavage and analysed by nanoLC-MS/MS (see below). In the negative-control assay, ATP was omitted from the kinase reaction.

NanoLC-MS/MS and data analysis. The nano HPLC system was comprised of an UltiMate 3000 HPLC RSLC nano system (Thermo Fisher Scientific) coupled to a Q Exactive mass spectrometer (Thermo Fisher Scientific), equipped with a Proxeon nanospray source (Thermo Fisher Scientific). Following proteolytic treatment of Rpa43-His6-HA, peptides were loaded onto a trap column (PepMap C18, $5 \mathrm{~mm} \times 300 \mu \mathrm{m}$ ID, $5 \mu \mathrm{m}$ particles, $100 \AA$ A pores; Thermo Fisher Scientific) at a flow rate of $25 \mu \mathrm{l} \mathrm{min}-1$ using $0.1 \%$ TFA as mobile phase. After $10 \mathrm{~min}$, the trap column was switched in line with the analytical column (PepMap C18,

$500 \mathrm{~mm} \times 75 \mu \mathrm{m} \mathrm{ID}, 3 \mu \mathrm{m}, 100 \AA$; Thermo Fisher Scientific). The peptides were eluted using a flow rate of $230 \mathrm{nl} \mathrm{min}^{-1}$, and a binary 2 -h gradient and a 165 -min gradient. The gradient starts with the mobile phases: $98 \%$ A (water/formic acid, 99.9/0.1, v/v) and 2\% B (water/acetonitrile/formic acid, 19.92/80/0.08, v/v/v) increases to $35 \% \mathrm{~B}$ over the next $120 \mathrm{~min}$, followed by a gradient in $5 \mathrm{~min}$ to $90 \% \mathrm{~B}$, stays there for $5 \mathrm{~min}$ and decreases in 5 min back to the gradient $98 \% \mathrm{~A}$ and $2 \% \mathrm{~B}$ for equilibration at $30^{\circ} \mathrm{C}$. The $\mathrm{Q}$ Exactive mass spectrometer was operated in datadependent mode, using a full scan $(\mathrm{m} / \mathrm{z}$ range $380-1,650$, nominal resolution of 70,000; target value 3E6) followed by MS/MS scans of the 12 most abundant ions. MS/MS spectra were acquired using normalized collision energy $27 \%$, isolation width of 2 and the target value was set to 1E5. Precursor ions selected for fragmentation (charge state 2 and higher) were put on a dynamic exclusion list for $10 \mathrm{~s}$. In addition, the underfill ratio was set to $20 \%$ resulting in an intensity threshold of $4 \mathrm{E} 4$. The peptide match feature and the exclude isotopes feature were enabled.

For peptide identification, the RAW files were loaded into Proteome Discoverer (version 1.4.0.288, Thermo Scientific). The created MS/MS spectra were searched using Mascot 2.2.07 (Matrix Science, Sequest, Thermo Scientific) ${ }^{68}$ and MSAmanda ${ }^{69}$ against the $S$. cerevisiae genome database ${ }^{25}$. The following search parameters were used: $\beta$-methylthiolation on cysteine was set as a fixed modification, mono- and dioxidation on methionine, acetylation on lysine and protein- $\mathrm{N}$ terminus, deamidation on asparagine and glutamine, mono- and dimethylation on lysine, and arginine and phosphorylation on serine, threonine and tyrosine were set as variable modifications. Monoisotopic masses were searched within unrestricted protein masses for tryptic and chymotryptic peptides. The peptide mass tolerance was set to $\pm 6 \mathrm{ppm}$ and the fragment mass tolerance to $\pm 30 \mathrm{mmu}$. The maximal number of missed cleavages was set to 2 . The result was filtered to $1 \%$ false discovery rate using the Percolator algorithm integrated in Proteome Discoverer (Thermo Scientific). The localization of the phosphorylation sites within the peptides was performed with ptmRS, based on the algorithm of phosphoRS ${ }^{70}$. The ion series of the Rpa43 QHLNPLVMKYNNK phospho-peptide are shown in Supplementary Table 4.

\section{References}

1. Tomson, B. N., D’Amours, D., Adamson, B. S., Aragon, L. \& Amon, A. Ribosomal DNA transcription-dependent processes interfere with chromosome segregation. Mol. Cell. Biol. 26, 6239-6247 (2006).

2. Sullivan, M., Higuchi, T., Katis, V. L. \& Uhlmann, F. Cdc14 phosphatase induces rDNA condensation and resolves cohesin-independent cohesion during budding yeast anaphase. Cell 117, 471-482 (2004).

3. D’Ambrosio, C., Kelly, G., Shirahige, K. \& Uhlmann, F. Condensin-dependent rDNA decatenation introduces a temporal pattern to chromosome segregation. Curr. Biol. 18, 1084-1089 (2008).

4. Clemente-Blanco, A. et al. Cdc14 inhibits transcription by RNA polymerase I during anaphase. Nature 458, 219-222 (2009).

5. Woolford, Jr J. L. \& Baserga, S. J. Ribosome biogenesis in the yeast Saccharomyces cerevisiae. Genetics 195, 643-681 (2013).

6. Thomson, E., Ferreira-Cerca, S. \& Hurt, E. Eukaryotic ribosome biogenesis at a glance. J. Cell. Sci. 126, 4815-4821 (2013).

7. D'Amours, D., Stegmeier, F. \& Amon, A. Cdc14 and condensin control the dissolution of cohesin-independent chromosome linkages at repeated DNA. Cell 117, 455-469 (2004).

8. Esser, D. \& Siebers, B. Atypical protein kinases of the RIO family in archaea. Biochem. Soc. Trans. 41, 399-404 (2013).
9. LaRonde-LeBlanc, N. \& Wlodawer, A. A family portrait of the RIO kinases. J. Biol. Chem. 280, 37297-37300 (2005).

10. LaRonde-LeBlanc, N. \& Wlodawer, A. The RIO kinases: an atypical protein kinase family required for ribosome biogenesis and cell cycle progression. Biochim. Biophys. Acta 1754, 14-24 (2005).

11. LaRonde, N. A. The ancient microbial RIO kinases. J. Biol. Chem. 289, 9488-9492 (2014).

12. Ferreira-Cerca, S., Kiburu, I., Thomson, E., LaRonde, N. \& Hurt, E. Dominant Riol kinase/ATPase catalytic mutant induces trapping of late pre-40S biogenesis factors in 80 S-like ribosomes. Nucleic Acids Res. 42, 8635-8647 (2014).

13. Ferreira-Cerca, S. et al. ATPase-dependent role of the atypical kinase Rio2 on the evolving pre-40S ribosomal subunit. Nat. Struct. Mol. Biol. 19, 1316-1323 (2012).

14. Perrochia, L., Guetta, D., Hecker, A., Forterre, P. \& Basta, T. Functional assignment of KEOPS/EKC complex subunits in the biosynthesis of the universal t6A tRNA modification. Nucleic Acids Res. 41, 9484-9499 (2013).

15. Vanrobays, E. et al. Processing of 20 S pre-rRNA to $18 \mathrm{~S}$ ribosomal RNA in yeast requires Rrp10p, an essential non-ribosomal cytoplasmic protein. EMBO J. 20, 4204-4213 (2001).

16. Vanrobays, E., Gelugne, J. P., Gleizes, P. E. \& Caizergues-Ferrer, M. Late cytoplasmic maturation of the small ribosomal subunit requires RIO proteins in Saccharomyces cerevisiae. Mol. Cell. Biol. 23, 2083-2095 (2003).

17. Hector, R. D. et al. Snapshots of pre-rRNA structural flexibility reveal eukaryotic $40 \mathrm{~S}$ assembly dynamics at nucleotide resolution. Nucleic Acids Res. 42, 12138-12154 (2014).

18. Turowski, T. W. et al. Riol mediates ATP-dependent final maturation of $40 \mathrm{~S}$ ribosomal subunits. Nucleic Acids Res. 42, 12189-12199 (2014).

19. Baumas, K. et al. Human RioK3 is a novel component of cytoplasmic pre-40S pre-ribosomal particles. RNA Biol. 9, 162-174 (2012).

20. Widmann, B. et al. The kinase activity of human Riol is required for final steps of cytoplasmic maturation of $40 \mathrm{~S}$ subunits. Mol. Biol. Cell 23, 22-35 (2012).

21. Angermayr, M., Roidl, A. \& Bandlow, W. Yeast Riolp is the founding member of a novel subfamily of protein serine kinases involved in the control of cell cycle progression. Mol. Microbiol. 44, 309-324 (2002).

22. Angermayr, M., Hochleitner, E., Lottspeich, F. \& Bandlow, W. Protein kinase CK2 activates the atypical Riolp kinase and promotes its cell-cycle phasedependent degradation in yeast. FEBS J. 274, 4654-4667 (2007).

23. Breitkreutz, A. et al. A global protein kinase and phosphatase interaction network in yeast. Science 328, 1043-1046 (2010).

24. Huang, J. \& Moazed, D. Association of the RENT complex with nontranscribed and coding regions of rDNA and a regional requirement for the replication fork block protein Fob1 in rDNA silencing. Genes Dev. 17, 2162-2176 (2003).

25. Cherry, J. M. et al. Saccharomyces Genome Database: the genomics resource of budding yeast. Nucleic Acids Res. 40, D700-D705 (2012).

26. Lempiainen, H. \& Shore, D. Growth control and ribosome biogenesis. Curr Opin. Cell. Biol. 21, 855-863 (2009).

27. Kobayashi, T. Ribosomal RNA gene repeats, their stability and cellular senescence. Proc. Jpn Acad. Ser. B Phys. Biol. Sci. 90, 119-129 (2014).

28. Tsang, E. \& Carr, A. M. Replication fork arrest, recombination and the maintenance of ribosomal DNA stability. DNA. Repair (Amst). 7, 1613-1623 (2008).

29. Ganley, A. R., Ide, S., Saka, K. \& Kobayashi, T. The effect of replication initiation on gene amplification in the rDNA and its relationship to aging. Mol Cell 35, 683-693 (2009).

30. Saka, K., Ide, S., Ganley, A. R. \& Kobayashi, T. Cellular senescence in yeast is regulated by rDNA noncoding transcription. Curr. Biol. 23, 1794-1798 (2013).

31. Visintin, R., Hwang, E. S. \& Amon, A. Cfil prevents premature exit from mitosis by anchoring Cdc14 phosphatase in the nucleolus. Nature 398, 818-823 (1999).

32. Tsang, C. K., Li, H. \& Zheng, X. S. Nutrient starvation promotes condensin loading to maintain rDNA stability. EMBO J. 26, 448-458 (2007).

33. Kobayashi, T., Horiuchi, T., Tongaonkar, P., Vu, L. \& Nomura, M. SIR2 regulates recombination between different $\mathrm{rDNA}$ repeats, but not recombination within individual rRNA genes in yeast. Cell 117, 441-453 (2004).

34. Eckert-Boulet, N. \& Lisby, M. Regulation of rDNA stability by sumoylation. DNA. Repair (Amst). 8, 507-516 (2009).

35. Pellicioli, A. et al. Activation of Rad53 kinase in response to DNA damage and its effect in modulating phosphorylation of the lagging strand DNA polymerase. EMBO J. 18, 6561-6572 (1999).

36. Kobayashi, T. \& Ganley, A. R. Recombination regulation by transcriptioninduced cohesin dissociation in rDNA repeats. Science 309, 1581-1584 (2005)

37. Michel, A. H., Kornmann, B., Dubrana, K. \& Shore, D. Spontaneous rDNA copy number variation modulates Sir2 levels and epigenetic gene silencing. Genes Dev. 19, 1199-1210 (2005)

38. Dragon, F. et al. A large nucleolar U3 ribonucleoprotein required for $18 \mathrm{~S}$ ribosomal RNA biogenesis. Nature 417, 967-970 (2002). 
39. Phipps, K. R., Charette, J. \& Baserga, S. J. The small subunit processome in ribosome biogenesis-progress and prospects. Wiley Interdiscip. Rev. RNA 2, 1-21 (2011).

40. Horn, D. M., Mason, S. L. \& Karbstein, K. Rcl1 protein, a novel nuclease for $18 \mathrm{~S}$ ribosomal RNA production. J. Biol. Chem. 286, 34082-34087 (2011).

41. Fujii, T., Yamaoka, H., Gomi, K., Kitamoto, K. \& Kumagai, C. Cloning and nucleotide sequence of the ribonuclease T1 gene (rntA) from Aspergillus oryzae and its expression in Saccharomyces cerevisiae and Aspergillus oryzae. Biosci. Biotechnol. Biochem. 59, 1869-1874 (1995).

42. Blattner, C. et al. Molecular basis of Rrn3-regulated RNA polymerase I initiation and cell growth. Genes Dev. 25, 2093-2105 (2011).

43. Stepanchick, A. et al. DNA binding by the ribosomal DNA transcription factor rrn3 is essential for ribosomal DNA transcription. J. Biol. Chem. 288, 9135-9144 (2013)

44. Kocher, T., Pichler, P., Swart, R. \& Mechtler, K. Analysis of protein mixtures from whole-cell extracts by single-run nanoLC-MS/MS using ultralong gradients. Nat. Protoc. 7, 882-890 (2012).

45. Laronde-Leblanc, N., Guszczynski, T., Copeland, T. \& Wlodawer, A. Structure and activity of the atypical serine kinase Riol. FEBS J. 272, 3698-3713 (2005).

46. Marin, O. et al. Tyrosine versus serine/threonine phosphorylation by protein kinase casein kinase-2. A study with peptide substrates derived from immunophilin Fpr3. J. Biol. Chem. 274, 29260-29265 (1999).

47. Wilson, L. K., Dhillon, N., Thorner, J. \& Martin, G. S. Casein kinase II catalyzes tyrosine phosphorylation of the yeast nucleolar immunophilin Fpr3. J. Biol. Chem. 272, 12961-12967 (1997).

48. Mekhail, K., Seebacher, J., Gygi, S. P. \& Moazed, D. Role for perinuclear chromosome tethering in maintenance of genome stability. Nature 456, 667-670 (2008)

49. He, X., Jones, M. H., Winey, M. \& Sazer, S. Mph1, a member of the Mps1-like family of dual specificity protein kinases, is required for the spindle checkpoint in S. pombe. J. Cell. Sci. 111, 1635-1647 (1998).

50. Wang, P. et al. II. Structure and specificity of the interaction between the FHA2 domain of Rad53 and phosphotyrosyl peptides. J. Mol. Biol. 302, 927-940 (2000).

51. Peng, J. et al. Dusty protein kinases: primary structure, gene evolution, tissue specific expression and unique features of the catalytic domain. Biochim. Biophys. Acta 1759, 562-572 (2006).

52. McMillan, J. N., Sia, R. A. \& Lew, D. J. A morphogenesis checkpoint monitors the actin cytoskeleton in yeast. J. Cell. Biol. 142, 1487-1499 (1998).

53. Gerber, J. et al. Site specific phosphorylation of yeast RNA polymerase I. Nucleic Acids Res. 36, 793-802 (2008).

54. Albuquerque, C. P. et al. A multidimensional chromatography technology for in-depth phosphoproteome analysis. Mol. Cell. Proteom. 7, 1389-1396 (2008).

55. Holt, L. J. et al. Global analysis of Cdk1 substrate phosphorylation sites provides insights into evolution. Science 325, 1682-1686 (2009).

56. Kuhn, C. D. et al. Functional architecture of RNA polymerase I. Cell 131, 1260-1272 (2007)

57. Fernandez-Tornero, C. et al. Crystal structure of the 14-subunit RNA polymerase I. Nature 502, 644-649 (2013).

58. Bernstein, K. A. \& Baserga, S. J. The small subunit processome is required for cell cycle progression at G1. Mol. Biol. Cell 15, 5038-5046 (2004)

59. Takeuchi, Y., Horiuchi, T. \& Kobayashi, T. Transcription-dependent recombination and the role of fork collision in yeast rDNA. Genes Dev. 17, 1497-1506 (2003)

60. Christman, M. F., Dietrich, F. S., Levin, N. A., Sadoff, B. U. \& Fink, G. R. The rRNA-encoding DNA array has an altered structure in topoisomerase I mutants of Saccharomyces cerevisiae. Proc. Natl Acad. Sci. USA 90, 7637-7641 (1993).

61. Kiburu, I. N. \& LaRonde-LeBlanc, N. Interaction of Rio1 kinase with toyocamycin reveals a conformational switch that controls oligomeric state and catalytic activity. PLoS ONE 7, e37371 (2012).
62. Auger-Buendia, M. A., Hamelin, R. \& Tavitian, A. Influence of toyocamycin on the assembly and processing of preribosomal ribonucleoproteins in the nucleolus of mammalian cells. Biochim. Biophys. Acta. 521, 241-250 (1978).

63. Heix, J. et al. Mitotic silencing of human rRNA synthesis: inactivation of the promoter selectivity factor SL1 by $\mathrm{cdc} 2 /$ cyclin B-mediated phosphorylation. EMBO J. 17, 7373-7381 (1998).

64. Sirri, V., Hernandez-Verdun, D. \& Roussel, P. Cyclin-dependent kinases govern formation and maintenance of the nucleolus. J. Cell Biol. 156, 969-981 (2002).

65. Leung, A. K. et al. Quantitative kinetic analysis of nucleolar breakdown and reassembly during mitosis in live human cells. J. Cell Biol. 166, 787-800 (2004).

66. Sagot, I., Bonneu, M., Balguerie, A. \& Aigle, M. Imaging fluorescence resonance energy transfer between two green fluorescent proteins in living yeast. FEBS Lett. 447, 53-57 (1999).

67. De Sanctis, V. et al. In vivo topography of Rap1p-DNA complex at Saccharomyces cerevisiae TEF2 UAS(RPG) during transcriptional regulation. J. Mol. Biol. 318, 333-349 (2002).

68. Eng, J. K., McCormack, A. L. \& Yates, J. R. An approach to correlate tandem mass spectral data of peptides with amino acid sequences in a protein database. J. Am. Soc. Mass Spect. 5, 976-989 (1994).

69. Dorfer, V. et al. J. Proteome Res. 13, 3679-3684 (2014)

70. Sievers, F. et al. Fast, scalable generation of high-quality protein multiple sequence alignments using Clustal Omega. Mol. Syst. Biol. 7, 539 (2011).

\section{Acknowledgements}

We thank A. Amon, M. Angermayr, L. Aragón, C. Cullin, D. D’Amours, M. Foiani, J.-P. Gelugne, K. Mekhail, M. Riva, E. Schiebel, T.U. Tanaka and F. Uhlmann for strain and reagents. We thank S. Pasqualato for help with the alignments and structure images, and D. Strau $\beta$, J. Griesenbeck, H. Tschochner, P. Milkereit and J. Perez-Fernandez for discussions. This research was supported by a Howard Hughes Medical Institute Inter national Early Career Scientist Grant and Investigator Grant 12878 from the Italian Association for Cancer Research to R.V., Investigator Grant 13243 from the Italian Association for Cancer Research to P.D.W., Austrian Science Fund FWF grants SFB F3402-B03, P2465-B24, TRP 308-N15, E.C. Seventh Framework Programme gran FP7/2007-2013, projects MEIOsys (222883-2) and PRIME-XS (262067) to K.M.

\section{Author contributions}

C.G., M.D.M. and V.I. initiated the project and created the 6 myc-riol $^{T E V}$ nuclear depletion strain. M.G.I. proceeded with the project, observed the Riol depletion phenotypes and performed most of the described experiments together with L.F.M.. C.P. produced recombinant Riol and Rpa43, and did the Riol-Sgs1 co-IP experiments. S.B. performed the Rio1-Rpa43 in vitro kinase assay, which was supervised by R.V. K.M. performed the mass spectrometric analysis of Riol-phosphorylated Rpa43. S.F.-C. performed the ribosome profiling experiments, the pulse-chase protein translation studies and pre-rRNA processing analyses by northern hybridization. P.D.W., M.G.I. and S.F.-C. conceived the experiments with the person(s) performing them. M.G.I., L.F.M., S.F.-C. and P.D.W. wrote the paper. All authors have approved of the manuscript.

\section{Additional information}

Supplementary Information accompanies this paper at http://www.nature.com/ naturecommunications

Competing financial interests: The authors declare no competing financial interests.

Reprints and permission information is available online at http://npg.nature.com/ reprintsandpermissions/

How to cite this article: Iacovella, M. G. et al. Riol promotes rDNA stability and downregulates RNA polymerase I to ensure rDNA segregation. Nat. Commun. 6:6643 doi: $10.1038 /$ ncomms7643 (2015) 